\title{
Eccentric, concentric and isometric strength in trained and untrained older adults
}

\author{
Fernando A. Rosete \\ Western Washington University
}

Follow this and additional works at: https://cedar.wwu.edu/wwuet

Part of the Kinesiology Commons

\section{Recommended Citation}

Rosete, Fernando A., "Eccentric, concentric and isometric strength in trained and untrained older adults" (2014). WWU Graduate School Collection. 372.

https://cedar.wwu.edu/wwuet/372

This Masters Thesis is brought to you for free and open access by the WWU Graduate and Undergraduate Scholarship at Western CEDAR. It has been accepted for inclusion in WWU Graduate School Collection by an authorized administrator of Western CEDAR. For more information, please contact westerncedar@wwu.edu. 
Eccentric, Concentric and Isometric Strength in Trained and Untrained Older Adults

By

Fernando A. Rosete

Accepted in Partial Completion

Of the Requirements for the Degree

Master of Science

Kathleen Kitto, Dean of the Graduate School

ADVISORY COMMITTEE

Chair, Dr. Lorraine R. Brilla

Dr. David N. Suprak

Dr. Jun San Juan 


\section{Master's Thesis}

In presenting this thesis in partial fulfillment of the requirements for a master's degree at Western Washington University, I grant to Western Washington University the non-exclusive royalty-free right to archive, reproduce, distribute, and display the thesis in any and all forms, including electronic format, via any digital library mechanisms maintained by WWU.

I represent and warrant this is my original work, and does not infringe or violate any rights of others. I warrant that I have obtained written permissions from the owner of any third party copyrighted material included in these files.

I acknowledge that I retain ownership rights to the copyright of this work, including but not limited to the right to use all or part of this work in future works, such as articles or books.

Library users are granted permission for individual, research and non-commercial reproduction of this work for educational purposes only. Any further digital posting of this document requires specific permission from the author.

Any copying or publication of this thesis for commercial purposes, or for financial gain, is not allowed without my written permission.

Signature: Fernando A. Rosete

Date: July, 2014 
Eccentric, Concentric and Isometric Strength in Trained and Untrained Older Adults

\author{
A Thesis Presented to \\ The Faculty of \\ Western Washington University \\ In Partial Fulfillment \\ Of the Requirements for the Degree \\ Master of Science
}

By

Fernando Rosete

July, 2014 


\begin{abstract}
The process of aging includes changes in muscle and connective tissue architecture and function, increased stiffness, loss of strength and functionality. Nonetheless, older adults are able to maintain eccentric (ECC) strength levels in a greater proportion, when compared to maintaining isometric (ISO) strength and concentric $(\mathrm{CON})$ strength. The purpose of this study was to compare CON, ECC and ISO leg extension torque between trained (T) and untrained (U) older adults. Twenty older adults (60 years and older) who had no knee pathologies were recruited. A Biodex dynamometer was used to measure leg extensor torque for ISO, CON and ECC, in T and U subjects. Torque values relative to body weight (relative torques) were determined for each subject and compared between groups. The ratio of ECC: ISO was calculated and compared across groups. The T group were significantly stronger for ISO $(p=0.009)$. No significant differences were found for CON $(p=0.088)$ and ECC $(p=0.220)$. In addition, the U group registered a significantly higher ratio of ECC: ISO $(p=0.029)$, when compared to the T group. The findings in this study demonstrate older adults are able to maintain ECC, regardless of training status.
\end{abstract}




\section{Acknowledgements}

I am indebted to many individuals whose participation and support made possible the completion of this thesis. Special thanks to all the willing subjects in this study, to the Bellingham and Blaine Senior centers and the Mature Adult Training Program at Western Washington University. The support during data collection provided by my peers, Sarah Viera and Joana Houplin was magnificent, helping me stay focused and on track.

It is with immense gratitude that I acknowledge the support of my advisor, Dr. Lorrie Brilla. She guided me in the completion of the preliminary requirements to enroll in this program. More importantly, she supported me through the process of completing this thesis. It would not have been possible without her patience, guidance and unconditional, tough love. The suggestions and friendly advice by Dr. Dave Suprak were immensely valuable. During my stay at WWU, Dr. Suprak was always available to answer questions and exchange ideas related to our field. He was always inspiring, both as a great professor and as a modest human being. Thanks to Dr. Jun San Juan, for sharing his experience, comments and advise during the thesis completion process.

Lastly, I would like to thank my family. Thanks to my parents for leading by example, for always inspiring and supporting my education. Thanks to my wife, for her loving support and for sharing this wild adventure. 


\section{Table of Contents}

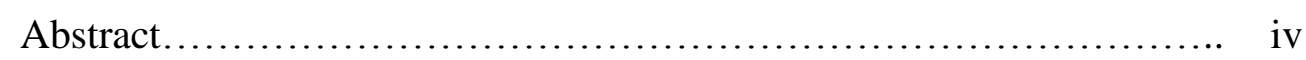

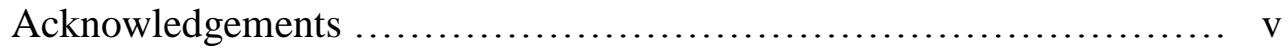

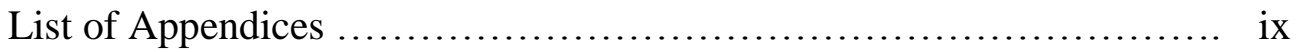

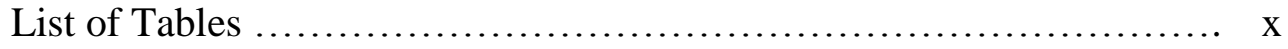

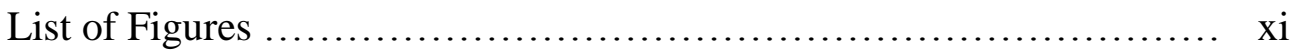

CHAPTER I The Problem and Its Scope

Introduction $\ldots \ldots \ldots \ldots \ldots \ldots \ldots \ldots \ldots \ldots \ldots \ldots \ldots \ldots \ldots \ldots \ldots \ldots \ldots, 1$

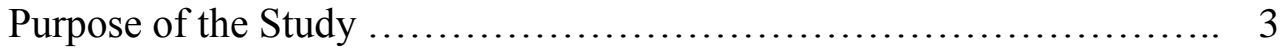

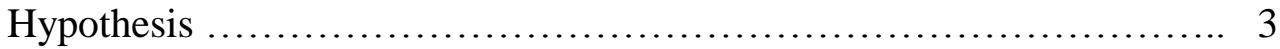

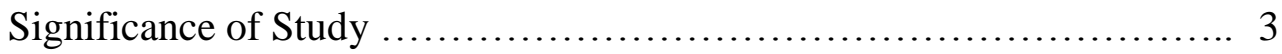

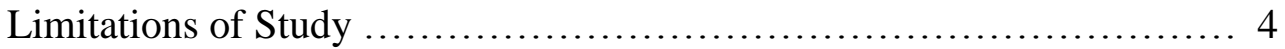

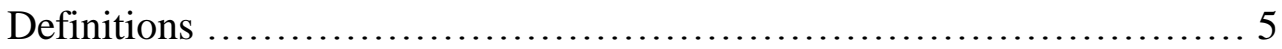

CHAPTER II Review of Literature

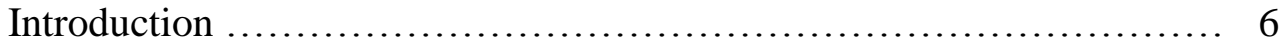

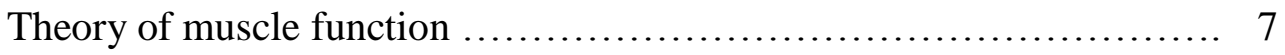

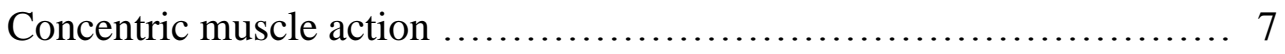


Isometric muscle action

Eccentric muscle action

Force transmission

Eccentric strength in older adults

Muscle attributes in older adults 16

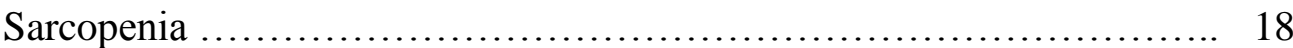

Sarcopenia effects on power production and functionality $\ldots \ldots \ldots \ldots \ldots .20$

Quality and functionality of muscle in older adults $\ldots \ldots \ldots \ldots \ldots \ldots \ldots . \ldots 23$

Regular resistance training effects in older adults ..................... 25

Eccentric resistance training in older adults $\ldots \ldots \ldots \ldots \ldots \ldots \ldots \ldots \ldots \ldots . \ldots \ldots$

The Biodex reliability......................................... 29

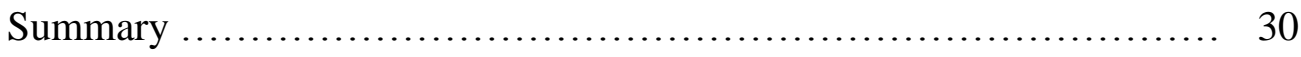

CHAPTER III Methods and Procedures

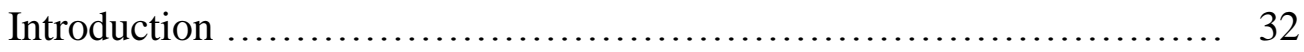

Description of Subjects....................................... 32

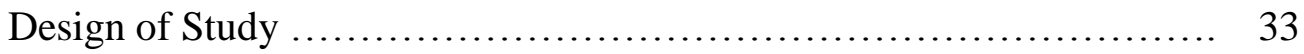

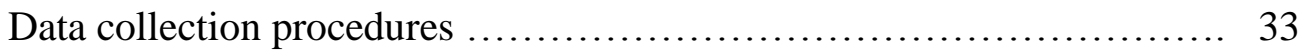

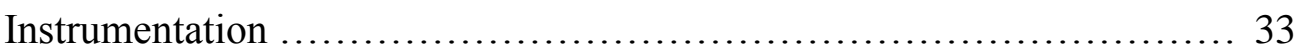

Description of technique and procedures ......................... 34 
Data Analysis

CHAPTER IV Results and Discussion

Introduction

Subject characteristics

Results 39

Discussion

Summary

CHAPTER V Summary and Conclusions

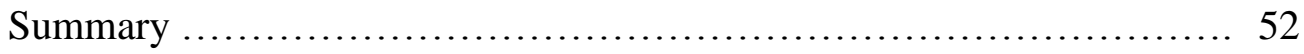

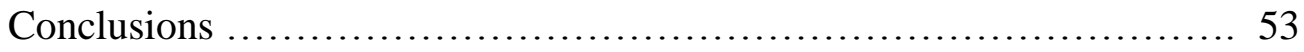

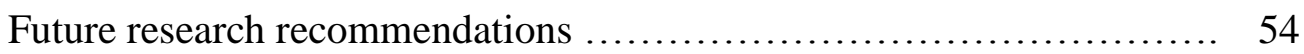

Practical applications ...................................... 54

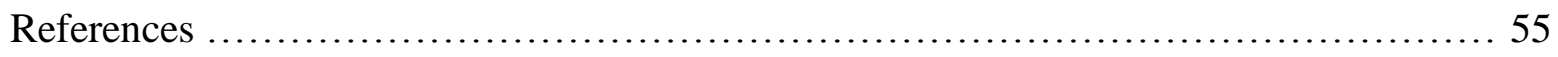

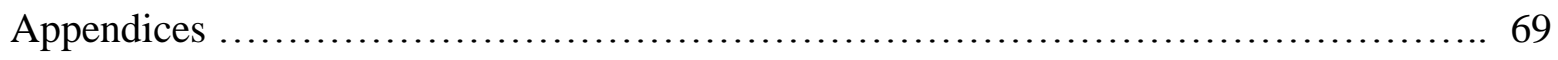


List of Appendices

Appendix A. Human subjects form and informed consent.............. 69

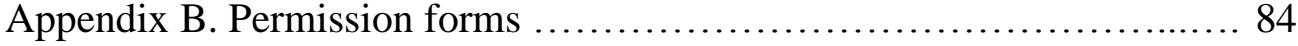

Appendix C. Physical activity readiness questionnaire (PAR-Q) ........ 87

Appendix D. Data collection form ................................. 90

Appendix E: Raw data ...................................... 92

Appendix F. Statistics tables ..................................... 94 
List of Tables

Table 1. Subjects' characteristics ................................. 38

Table 2. Descriptive statistics ....................................... 39

Table 3. Results of isokinetic testing in trained versus untrained older

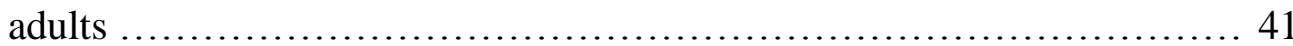




\section{List of Figures}

Figure 1. Biodex graphic representing leg extension forces in $\mathrm{Nm}$ during

ISO testing

Figure 2. Leg extension absolute peak torque values

Figure 3. Eccentric to isometric ratio and ISO, ECC and CON relative strength 


\section{Chapter I}

\section{The Problem and Its Scope}

\section{Introduction}

The human aging process has been extensively studied, looking for viable ways to maintain functionality and quality of life. Strength and power have been recognized as highly relevant measures of quality of life for elderly populations (Silanpaa, Hakkinen, Holviala, \& Hakkinen, 2012). Even though strength levels decrease with age, eccentric (ECC) is maintained longer when compared to concentric (CON) and isometric (ISO) in older adults (Power, Rice \& Vandervoort, 2012). However, the comparison of ECC between trained and untrained older adults has not been measured. ECC is considered especially important for older populations. The natural function of generating force during muscle lengthening is to decelerate external and internal forces, which is important for daily function and injury prevention. ECC improves posture and helps maintain balance. Thus, ECC reduces the risk of falling, while improving functionality and overall quality of life (Wu, Zhao, Zhou, \& Wei, 2002). Older adults undergo structural changes in muscle fibers and connective tissue that are helpful to maintain ECC. Such changes include increased stiffness in connective tissue that enhances the capacity of muscles to generate elastic forces while lengthening. Greater stiffness in tendons adds the capacity of accumulating greater forces during stretch, while generating higher, passive resistance. Thus, older adults become more efficient at doing eccentric work (Klass, Baudry, \& Duchateau, 2005; Lindle, et al., 1997).

Multiple factors have been considered to justify the loss of strength and physical performance in older adults, affecting gait speed, balance, endurance, and increasing risk for falls (Fried, et al., 2001). Sarcopenia and cachexia have been studied, compared and defined as the 
most common conditions that result in the loss of muscle mass consequently diminishing strength levels (Evans, Morley, \& Argiles, 2008; Rolland, Abellan, Gillette-Guyonnet, \& Vellas, 2011). Cachexia is considered a metabolic syndrome, involving overall weight loss in older adults, with a substantial reduction in muscle mass and an increased adipose tissue infiltration into muscles (Evans, et al., 2008). Cachexia is characterized specifically by inflammation and increased protein breakdown that could cause chronic infections, potentially affecting kidneys, causing pulmonary disease and heart failure, along with the breakdown of muscle tissue during the process leading to sarcopenia (Rolland, et al., 2011; Evans, et al., 2008). Furthermore, Rolland et al. (2011) describe sarcopenia cases as multifactorial, considering the following causes as possible roots of the condition: sedentary lifestyle, inactivity, immobilization, malnutrition, adverse drug reactions, inflammatory diseases, or malignancy. Some researchers have emphasized the detrimental effects of osteoporosis on bone strength, along with its negative impact on overall functionality (Woo, Leung, \& Lau, 2009).

Even in the absence of disease, natural mechanisms of aging have a detrimental effect on muscle strength. For instance, apoptosis is a process of cellular self-programming for destruction. Apoptopic signals in muscle cells could target single nuclei within a muscle cell, without the destruction of the whole cell, but reducing its size. This mechanism, known as nuclear apoptosis, is recognized as a fundamental mechanism of aging-induced muscle loss leading to sarcopenia, by reducing the possible myofiber volume supported in a single muscle fiber (Always \& Siu, 2011). In addition, both myonuclei and satellite cells seem to be susceptible to nuclear apoptosis in sarcopenia, leading to DNA fragmentation and eventually the complete destruction of muscle cells (Alway \& Siu, 2011; Marzetti, E., Calvani, R, Bernabei, R. \& Leeuwenburgh, C., 2011). However, increased, chronic physical activity is known to attenuate 
apoptopic signaling, possibly reducing sarcopenia and supporting strength maintenance (Alway \& Siu, 2011). Liu and Latham (2009) conclude muscle weakness is linked to a decline in physical activity in older populations.

\section{Purpose of the Study}

This study was designed to compare concentric (CON) strength, eccentric (ECC) strength and isometric (ISO) strength between trained and untrained older adults. Strength levels were represented by leg extensor torque measurements. Absolute and relative values of leg extensor CON torque, ECC torque and ISO torque were evaluated and compared in trained and untrained older subjects. The results could help illustrate potential strength differences between trained and untrained older adults during different muscle actions.

\section{Hypothesis}

There will be no significant difference in eccentric, concentric, and isometric torque or eccentric to isometric torque ratio between trained and untrained older adults.

\section{Significance of the Study}

The results could help illustrate how changes in muscle and connective tissue are useful to maintain ECC during older age. Even though there are many studies that explore the mechanisms of strength loss with aging, the differences in ECC between trained and untrained older adults have not been measured. This study contributes to further understanding the maintenance of ECC in older adults and could help illustrate a possible interaction between training status and ECC strength in older adults.

The research findings could serve as valuable information with practical implications for training professionals. The age specific advantages or disadvantages for using concentric (CON), 
isometric (ISO) and eccentric (ECC) muscle actions should be considered when designing resistance training programs for older populations.

\section{Limitations}

1. The trained group in this study has participated in a machine based resistance training program, which does not include specific eccentric training exercises.

2. For the purpose of this study, only older adults were considered (over 60 years old). Therefore, no possible comparison was made to younger subjects.

3. Due to the relevance of the quadriceps musculature for functionality and safety (e.g., walking, descending stairs, preventing falls), isometric, concentric and eccentric strength were measured exclusively in those muscles. However, the hip extensors and trunk musculature play an important role in balance and postural alignment as well.

4. Only the dominant side of the body was assessed for all subjects. Subjects with a previous total knee replacement were excluded from the study.

5. Isokinetic muscle actions were measured only at a speed of $120^{\circ} / \mathrm{s}$. Thus, there was no possible comparison of torque variation at different speeds.

6. Peak isometric torque was only assessed at $50^{\circ}$ of knee flexion.

7. When assigning subjects to each group (trained or untrained), the decision was made exclusively based on the subject's statement of current training status, with no other possible mechanism of control. That is, if the subject stated he/she had resistance trained at least twice per week, consistently, during the last 6 months, he/she would be considered as "trained." 


\section{Definitions}

Apoptosis - Cell programming for self-destruction, through channels that eventually lead to DNA fragmentation (Always \& Siu, 2011).

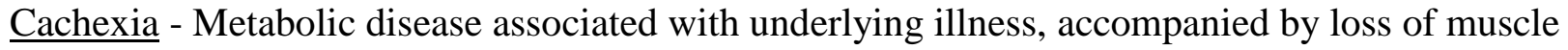
mass with or without loss of fat mass (Evans, et al., 2008).

Concentric strength (CON) - The capacity of a muscle to produce force, as muscle fibers shorten (Spudich, 2001).

Eccentric strength (ECC) - the capacity of producing force as a muscle undergoes lengthening as it resists an external load (Joumma, Leonard \& Herzog, 2008).

Isometric strength (ISO) - The capacity of a muscle to produce force with no apparent change in length in the same muscle (Fukashiro, \& Fukunaga, 1998).

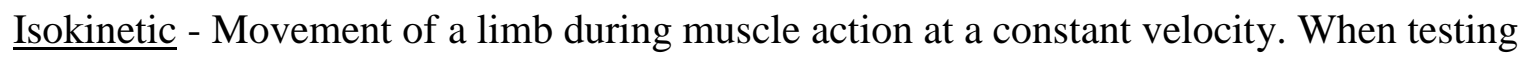
strength in an isokinetic dynamometer, the machine increases the load as it senses a possible increase in the velocity of the limb caused by muscle action (Neil, et al., 2013).

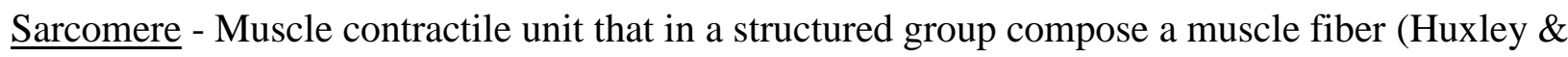
Niedergerke, 1954).

$\underline{\text { Sarcopenia }}$ - The loss of muscle mass due to aging, disuse, poor nutrition or malabsorption, or other physiological causes, such as abnormal thyroid function (Crus-Jentoft, et al., 2010).

$\underline{\text { Torque }}-\mathrm{A}$ moment of force causing rotation about an axis. When referring to muscle actions, it could be expressed as concentric torque, eccentric torque and isometric torque, depending on the nature of the muscle action (Harman, 1993). 


\section{Chapter II}

\section{Literature Review}

\section{Introduction}

It has been established that the aging process includes a decline in strength levels for concentric $(\mathrm{CON})$ strength and isometric (ISO) strength, with a lower decline in eccentric (ECC) strength. The goal of this study is to compare CON, ISO and ECC between trained and untrained older adults and establish a possible difference between groups.

Within this literature review, an overview of muscle function is presented, along with the differentiation of eccentric muscle action in terms of energy efficiency, strength capacity, and force transmission via the series elastic elements and the extracellular matrix (ECM). The natural mechanisms of aging that affect strength and skeletal muscle function are discussed for a better understanding of their overall negative impact in older adults. An explanation of the effects of resistance training (RT) is presented to create a baseline that defines the difference between resistance trained and untrained subjects. The effects of eccentric training are discussed in an effort to elucidate its benefits and to support a deeper understanding of ECC. The importance of ECC in the elderly is introduced, as a possible solution to manage the effects of aging in skeletal muscle and functionality. An introduction to the Biodex and its utilization is discussed in this section. 


\section{Theory of muscle function}

Muscle function is based on the interaction of the central and peripheral nervous systems, as they signal specific muscles to create movement. Each motoneuron is interfaced to several muscle fibers, composing a motor unit (MU). When a MU is activated, all of the fibers innervated by the activated motoneuron will be signaled to contract (Kallio, et al., 2013). The contractile proteins on the signaled muscles undergo biochemical processes that produce muscle action, resulting in increased tension and force production. During concentric muscle action (CON) or muscle contraction (shortening), the largest MU discharge occurs, while some muscles shorten and others lengthen on opposite sides of a joint, allowing changes in joint angle. In contrast, during isometric muscle action (ISO) fewer MUs are discharged, as muscles around a joint are activated, with no apparent change in joint angle. While studying the activity of the soleus, the lowest MU activation was observed during eccentric muscle action (ECC), as the muscle produced forces while lengthening, taking advantage of the elastic properties of muscle fibers and connective tissue (Kallio, et al., 2013).

\section{Concentric muscle action}

CON involves two contractile proteins in muscle, myosin and actin. After an alpha motoneuron sends an efferent signal to the innervated muscle fibers that compose the motor unit, a chemico-electrical depolarization process begins within each activated muscle cell (Grinnell \& Brazier, 1981). The sodium (Na) voltage gated channels on the sarcolemma open, allowing $\mathrm{Na}$ into the cell, increasing the voltage along the cell membrane. Once the voltage reaches the threshold, an action potential is conducted within the muscle cell. The signal is transmitted by the T-tubules to the sarcoplasmic reticulum, where calcium $(\mathrm{Ca})$ is released from the terminal cisternae. The proteins, myosin and actin, are in relaxed state, while the myosin heads are weakly 
bound to actin, as tropomyosin is blocking the attachment points. Once calcium is actively transported into the sarcomere, calcium binds to troponin, which removes the block and the myosin heads attach strongly to actin. The force generated is due to the myosin heads as they endure a rotation movement about a lever arm while attached to actin, creating a stroke like action powered by the energy released during ATP hydrolysis and ADP release (Spudich, 2001). After each stroke, the myosin heads require an ATP molecule to detach. The process continues for as long as Ca and ATP are present in the sarcomere (Huxley \& Niedergerke, 1954).

The sliding filament theory has been a dogmatic explanation for muscle contraction. Such a theory has left out additional factors relevant to the possible mechanisms of muscle action. Those mechanisms will be discussed more in depth in a following section.

\section{Isometric muscle action}

The term isometric implies no change in length, which could suggest that during isometric muscle action (ISO) force is produced by simply maintaining the cross bridge active state, without an apparent change in length in muscle fibers (Ito, Kawakami, Ichinose, Fukashiro, \& Fukunaga, 1998). However, there is a decrease in fascicle length during ISO, along with an increase in pennation angle in agonist muscles due to the sarcomere shortening, in compensatory response to the tendon elongation. Ito, et al. (1998) used ultrasonography to measure changes in fascicle length during ISO dorsiflexion of human tibialis anterior, in vivo. Fascicle length shortened from $90 \pm 7$ to $76 \pm 7 \mathrm{~mm}$, pennation angle increased from $10 \pm 1$ to $12 \pm 1^{\circ}$, and tendon elongation increased up to $15 \pm 2 \mathrm{~mm}$, during maximum voluntary contraction. In addition, Ito, et al. (1998) noticed an increase in tendon stiffness with augmented tendon strength from $10 \mathrm{~N} / \mathrm{mm}$ at $0-20 \mathrm{~N}$ to $32 \mathrm{~N} / \mathrm{mm}$ at 240-260 N. Small pennation angle changes during 
antagonist ISO results in an increased force transmission to the tendon (Simoneau, Longo, Seynnes, \& Narici 2012).

Purslow (2010) suggests forces are transmitted from fiber to fiber by shear forces, via the extracellular matrix. A group of fibers form a fascicle, which is covered by connective tissue known as perimysium. It is possible that forces are also transmitted from fascicle to fascicle (Purslow, 2010). As pennation angles increase, forces are transmitted to tendons which have the potential to store the energy and transmit that energy to surrounding muscles (Purslow, 2010).

Simoneau, et al. (2012) measured pennation angle changes in gastrocnemius (GM) length while subjects performed sub maximal plantar flexion. Fiber length of GM $(3.2 \pm 0.6 \mathrm{~cm})$ was significantly shorter compared to resting conditions $(3.8 \pm 0.7 \mathrm{~cm})(-16 \%)$. During sarcomere shortening, the GM muscle's cross-sectional area increased, augmenting the pennation angle $\left(31.6 \pm 7.1^{\circ}\right)$, which was significantly larger than while at rest $\left(26.1 \pm 5.4^{\circ},+21 \%\right)$, and larger than during ISO dorsiflexion $\left(24.7 \pm 5.5^{\circ},+28 \%\right)$, when GM acted as an antagonist.

During a recent study, Akagi, et al. (2012) measured the perpendicular distance between the joint center of rotation of the arm to the line of action of the arm's flexor muscles. That distance is known as moment arm (MA). MA at rest was compared to MA during ISO, at 50 ${ }^{\circ}$, $80^{\circ}$ and $110^{\circ}$ of elbow flexion, demonstrating larger MA during isometric contractions. The largest MA increase was measured at $110^{\circ}(68.1 \% \pm 32.9 \%$, at $20 \% \mathrm{MVC}$ and $77.8 \% \pm 44.8 \%$, at $60 \%$ MVC), as muscle fibers increased thickness. All ISO conditions were accompanied by an elongation of the tendon and decreased muscle slack, resulting in greater MA lengths for the arm flexor muscles, in comparison to resting MA lengths (Akagi, et al., 2012).

According to the previously described findings, during ISO, there are changes in muscle pennation angle, decrease in fascicle length, tendon elongation, and increases in muscle 
thickness. Muscle forces are transmitted longitudinally from and into tendons, and radially, between muscle fibers, between fascicles and from muscle to muscle.

\section{Eccentric muscle action}

In contrast to CON and ISO, when eccentric muscle action (ECC) occurs, the sarcomeres stretch under load, deforming the cross-bridges between filaments. Muscles elongate while resisting the stretch, as the links between actin and myosin detach, depending on ATP (Enoka, 1996). ECC capitalizes on the accumulation of elastic energy during sarcomere lengthening (Joumaa, Leonard \& Herzog, 2008). During lengthening, sarcomere stiffness is reduced, allowing muscle to "give" with the implementation of the series elastic element, consisting of the tendinous tissue connected in series with muscles, with the capacity of stretching while storing elastic energy (Flitney, \& Hirst, 1978).

In more recent studies, Roberts \& Azizi (2010) refer to "springy tissues" in muscles and connective tissue (e.g., tendons) and their capacity of stretching while storing elastic strain energy as force is applied to them and recoiling later to release energy, when force is reduced. Roberts \& Azizi (2011) asserted that tendons have three times the energy storage capacity of muscle fascicles. During their investigation, Roberts \& Azizi (2011) described tendons as ECC mechanical buffers. They measured peak instantaneous power input to the muscle tendon unit of $-2,143.9 \mathrm{~W} / \mathrm{kg}$, while peak power input to the fascicles was only $-557.6 \mathrm{~W} / \mathrm{kg}$ in lateral gastrocnemius of wild turkeys. Such findings explain how tendons could act as mechanical buffers, decelerating and limiting peak forces and lengthening rates as a protection mechanism, while absorbing energy during ECC. 
The spring like structures within muscle sarcomeres include titin, which is attached to myosin in the A-band region of the sarcomere, and assists with axial alignment during muscle actions while providing stability to adjacent sarcomeres (Horowits, Kempner, Bisher, \& Podolsky, 1986). Titin elongates in the I-band region of the sarcomere, working as a molecular spring while accumulating passive energy under active stretch (Kellermayer, Smith, Granzier, \& Bustamante, 1997). Nevertheless, Herzog, Duvall, \& Leonard (2012) explain how during active stretch, calcium binds titin, followed by an actin-titin binding in the I-band region. As actin binds with titin, the free spring length is shortened, increasing titin's stiffness. With increased stiffness, titin enhances its elastic force accumulation capabilities, while improving force production during ECC.

During ECC, energy is stored in elastic elements of muscle and tendon. The amount of energy accumulated depends on the muscle action history and rate of muscle loading at a given time, which influences the amount of force produced. The rate of loading is positively correlated to the energy accumulated. Further, rate of loading and energy accumulated have a positive effect on enhanced force capacity (Power, Rice, \& Vandervoort, 2012).

\section{Force transmission}

Force is transmitted radially and not only longitudinally (Williams, Regnier \& Daniel, 2012) as it is sensed across cellular structures with the aid of integrins. Integrins are proteins that serve as transmembrane receptors sensitive to chemical and mechanical status of the extracellular matrix (ECM) (Schwartz, 2010). Integrins connect actin filaments with ECM fibers transmitting forces inside and outside the muscle cell through a clutching system. Recent studies demonstrate the ECM supports most of the passive loads, which suggests increased stiffness and limited 
range of motion could be a direct measure of ECM status (Schwartz, 2010). Such increased stiffness could be useful for the maintenance of ECC in older adults and could also be helpful promoting efficiency for greater force return during and after stretch.

For example, Hobara, et al. (2008) compared leg and joint stiffness between endurance and power athletes, while hopping. The increased stiffness in power athletes helped them achieve greater aerial times $(483 \pm 17 \mathrm{~ms})$ compared to the endurance group $(438 \pm 22 \mathrm{~ms})$, with a significantly shorter contraction time for the power group (178 $\pm 13 \mathrm{~ms})$ compared to the endurance athletes $(211 \pm 24 \mathrm{~ms})$. The power group's superiority could be attributed to their greater capacity of accumulating elastic forces in their stiffer tendons during ECC. Therefore, the power group subjects were able to release the previously accumulated elastic forces in a shorter time during CON.

In another study, the acute effects of muscle stretching were tested on subjects sustaining submaximal ISO of the plantar flexors. The fluctuation of isometric torque was measured, demonstrating that during stretch, passive torque decreased as fascicle length increased. During the first stretch, the mean passive torque was $35.4 \pm 13.9 \mathrm{Nm}$, decreasing thereafter by $17.1 \pm$ $7.4 \%$, by the end of the $60 \mathrm{~s}$. For the fifth stretch, the mean passive torque at the beginning of the stretch reached $29.9 \pm 10.4 \mathrm{Nm}$ and declined thereafter by only $9.6 \pm 2.4 \%$. The changes in those measurements were significantly associated $\left(r^{2}=0.46\right)$, along with a significant increase in EMG $(p<0.05)$. The findings suggest there was a higher contribution of active mechanisms for force production, with a reduced reliability on the passive mechanisms, such as the elastic elements (Kato, Vieillevoye, Balestra, Guissard \& Duchateau, 2010). Such phenomena could be related to the possible advantage of increased muscle stiffness during old age, for the greater accumulation of passive, elastic force during ECC and its release during CON. 


\section{Eccentric strength in older adults}

Klass, et al. (2005) compared torque capacity in dorsiflexors of younger and older adults. The investigators measured isometric (ISO) torque, concentric (CON) torque, and eccentric (ECC) torque. Even though the younger group demonstrated overall greater ISO (20.5\%) and $\mathrm{CON}(38.6 \%)$, the superiority of the younger group was considerably lower for ECC (6.5\%). In fact, for women subjects, ECC was similar between young and older adults. After normalizing the $\mathrm{CON}$ and ECC to the maximal ISO, the CON demonstrated a significant mean reduction with age of $24.9 \pm 1.4 \%$ for women and $18.8 \pm 3.1 \%$ for men, with no significant difference between sexes. Conversely, relative ECC was higher for the older adult group, with an increased difference for women $(23.1 \pm 1.5 \%)$ than for men $(11 \pm 1.4 \%)$. Despite the level of physical activity, the maintenance of ECC strength in older adults is well documented (Klass, Baudry, \& Duchateau, 2005) when compared to ISO strength and CON strength.

A possible explanation for the capability of maintaining ECC is the increased antagonist with reduced agonist action of prime movers (muscle coactivation) as a common alteration identified in motor activity patterns for older populations during concentric muscle actions (Power et al., 2012). In contrast to such an explanation, Klass et al. (2005) found no age dependent differences in coactivation of agonist/antagonist in men and women. In addition, the investigators (Klass et al. 2005) measured voluntary activation of dorsiflexors in men and women, young and old. Testing was performed with velocities between 50 and $100^{\circ} /$ s, during ECC. The median of voluntary activation appeared to be maximum, or near maximum, at all velocities, with no differences in activation level between older and younger subjects. The average myoelectrical activity (EMG) activity of tibialis anterior during CON, ISO and ECC did not show a significant difference between young and old adults, regardless of velocity. 
Pousson, Leppers, \& Van Hoecke (2001) measured constant angular torque and EMG in the arm flexors, comparing older versus younger adults. The measurements taken included: ECC, ISO and CON. The average age for the elderly group was 69 , in comparison to the young group, with an average of 21 years of age. CON values were significantly lower for older subjects at 180 and $240^{\circ} \mathrm{s}^{-1}$. Conversely, older adults showed significant superiority in relative ECC, compared to the young group, at -120 and $-60^{\circ} \mathrm{s}^{-1}$.

Lindle, et al. (1997) compared leg extensor strength in 654 men and women aged 20-93 years. They measured peak CON and ECC at slow (0.52 rad/s) and fast (3.14 rad/s) velocity. A regression analysis demonstrated a significant decline in $\mathrm{CON}$ and ECC in older adults. However, there was a more substantial decline in CON (30\%) compared to ECC (19\%) in men, and a lower decline in CON (28\%) and ECC (11\%) for women. The results of the study suggest that older women have a greater capacity of storing and utilizing elastic energy, in comparison to men in the same age group (Lindle, et. al 1997).

There are alternative explanations for the maintained ECC in older adults, related to noncontractile, structural properties of muscle. The increase in muscle series elastic stiffness augments passive resistance during lengthening, increasing elastic energy accumulation and increasing force production by individual cross bridges during ECC (Ochala, Dorer, Frontera, \& Krivickas 2006). There are reported changes in elastic or structural properties in muscle fibers, independent of cross-bridge formation that could be supportive of ECC in older adults, such as the elevation of tension in single muscle fibers following a quick active stretch.

During their experiment, Ochala, et al. (2005) measured the tension increments after a quick stretch in single muscle fibers of vastus lateralis of old and young adults. A quick stretch causes an immediate increase in tension (T0, phase 1) followed by a decrease (T2, phase 2), and 
a second increase in tension, known as "stretch activation" (T3, phase 3). In the end, tension returns to steady state value (T4, phase4). Measurements of amplitudes of tension during phase 1 , phase 3 and phase 4 were recorded. In addition, the time change between the onset of the stretch and the peak value of the stretch activation was documented as T3. The findings illustrated a decrease in ISO tension $\left(\mathrm{T} 0=12.38 \mathrm{~N} / \mathrm{cm}^{2}\right)$ in older men, compared to younger (T0 $=16.51 \mathrm{~N} / \mathrm{cm}^{2}$ ) men. The tension enhancement was maintained after stretch during phase 3 and phase 4 for older men, as T3 and T4 $=0.22 \mathrm{~N} / \mathrm{cm}^{2}$, while younger men's was reduced T3 $=0.19$, $\mathrm{T} 4=0.17 \mathrm{~N} / \mathrm{cm}^{2}$.

The total force produced is a combination of passive and active forces generated by the interaction of the elastic, contractile and parallel elements in muscle. The active forces are produced by the interaction of actin and myosin. In contrast, the passive (elastic) force is produced by the elastic elements (e.g. titin and tendons) attached in series to the contractile elements. Furthermore, the parallel element is formed by connective tissue, surrounding each fiber, each fascicle and each muscle known as endomysium, perimysium and epimysium, respectively (Herzog, et al. 2012). During late adulthood, the augmentation in connective tissue and increased collagen cross-linking improves the tendon-sarcomere connections, providing an added mechanical resistance to stretch that could contribute to passive force development (Pousson, Lepers, \& Van Hoecke, 2001). In addition, there is an increase in muscle viscosity (Martin, Borlon, Pousson, \& Van Hoecke, 1996) that could limit CON, as muscles have to overcome the viscous resistance of the muscle itself while shortening.

Martin, et al. (1996) used a model of a viscous damper linked in parallel with a contractile component, and both connected in series with an elastic component. The model estimated a damping coefficient (DC) of the elbow flexors during CON and ECC. The DC was 
greater for CON compared to ECC and decreased as velocity increased, regardless of the type of muscle action. Martin explains the concentric loss and eccentric gain of force are due to the behavior of the contractile elements. The faster a muscle contracts, it has to overcome not only the external force, but the changes in viscosity that result in wasted energy. In contrast, ECC gained force during its action.

Titin plays a major role during ECC, acting as a spring and increasing overall stiffness and force capabilities in the sarcomere, which explains the residual force enhancement capabilities of muscle with age as muscle stiffness increases on the sarcomere (Herzog, et al., 2012). Leonard, et al. (2010) demonstrated how when removing titin from a sarcomere, all forces were eliminated in actively and passively stretched rabbit psoas myofibrils.

ECC becomes especially important during old age, when CON and ISO capabilities are typically more affected. ECC functions as a protective mechanism that could diminish risk of injuries, while promoting functionality, and may be considered a possible solution to manage some common challenges during of aging (Herzog, et al., 2012; Pousson, et al., 2001).

\section{Muscle attributes in older adults}

Changes in muscle attributes take place with age and affect muscle functionality. Such changes include nuclear apoptosis (NA); the death of a nucleus or nuclei of a muscle cell, without the death of the cell, but with a consequent reduction in size. The muscle fiber sectional area will be limited by the number of available nuclei. Satellite cells and muscle cells are susceptible to NA during sarcopenia. The loss of satellite cells reduces the muscle's capacity of replacing death nuclei. Thus, NA is the main cause of reduced muscle mass (sarcopenia), and the loss of strength and functionality (dynapenia). Satellite cells and muscle cells are susceptible to NA during sarcopenia (Alway \& Siu, 2011). Moreover, type II muscle fibers are more 
susceptible to atrophy due to their denervation from motoneurons. The denervation process is associated with a decrease in the number of myelinated neuronal axons in fast twitch motor units (Deschenes, 2004).

A loss in power production (force $\mathrm{x}$ velocity) has been observed in older adults' muscles. Nevertheless, power loss is just partially related to the loss of muscle mass. Vaillancourt, Larsson, \& Newell (2003) used intramuscular, fine-wire electromyography (EMG) to measure motor unit activation during isometric, maximum voluntary contractions (MVC) in hand muscles. When comparing a young group $(n=10$; mean: $22 \pm 1$ years $)$, to an old group $(n=10$; mean: $67 \pm 2$ years), and oldest group ( $\mathrm{n}=10$; mean: $82 \pm 5$ years), the young was strongest, with a mean force of $20.10 \mathrm{~N}$, in comparison to18.33 N, and $12.99 \mathrm{~N}$, respectively. An aging effect was identified and attributed to a lower MVC measured in the oldest group, in comparison to the old and young groups. More importantly, a shift towards the firing of slow $(10 \mathrm{~Hz}) \mathrm{motor}$ units from the faster $(40 \mathrm{~Hz})$ was observed in older subjects. Such findings demonstrate older adults depend on low-threshold motor units to produce MVCs, in comparison to younger subjects, limiting their capacity of power production.

Additional changes in muscle fibers include a reduction in pennation angle and a reduction in fascicle length. Power, Makrakos, Rice, \& Vandervoort (2013) measured architectural changes in muscle fibers using ultrasound imaging. When comparing older to younger adults, Power, et al. (2013) found significant differences between groups. Muscle fascicles were shorter $(\sim 18 \%)$ and less pennated $(\sim 22 \%)$ for the older adult group, when compared to younger adults.

In animal studies, Brack, Bildsoe \& Hughes (2005) isolated mice muscle fibers for analysis, comparing aged (26-29 months) and younger (2 months, 12 months, 22-24 months) 
mice. Young animal fibers showed nuclei with uniform morphology, in alignment with the fiber axis. Conversely, old fibers had variable shaped nuclei. About $22 \%$ of fibers for $22-24$ months old mice and 25\% from 26-29 months old mice had longer nuclei, compared to younger subjects'. Moreover, fiber size varied with age; with a 33\% mean fiber size reduction for the 2629 months old mice, when compared to the $12 \mathrm{~m}(p=0.008)$ group (adults). Nuclear number per unit length of fiber declined with age $(p=0.0001)$, demonstrating hypertrophy of fast twitch fibers after 24 months of age. The loss of nuclei/unit length in ageing muscle fibers could lead to sarcopenia (Brack et al., 2005).

Changes in motor recruitment strategies have been reported in old adults. Hortobagyi \& DeVita (2000) compared leg stiffness in young and old adults during downward stepping. The authors reported that elders had 64\% greater stiffness during downward stepping. Muscle activity during $200 \mathrm{~ms}$ previous to touchdown was $136 \%$ greater for the elders, and biceps femoris and tibialis anterior coactivity was also $120 \%$ greater during ground contact for the older adults. The muscle pre-activation and coactivity in the older group represented about $50 \%$ of the difference in leg stiffness between groups. An elevation in muscle coactivity could serve as a protective mechanism to increase joint stability, in compensation to reduced muscle strength in older adults. Sarcopenia. Originally defined as the loss of muscle mass resulting from the effects of aging, the concept of sarcopenia has evolved, as muscle mass loss is now considered multifactorial (Cruz-Jentoft, et al., 2010; van Kan, 2009). The loss of muscle tissue could be originated by disuse, poor nutrition or malabsorption, or other physiological causes, such as abnormal thyroid function (Cruz-Jentoft, et al., 2010).

Reid, et al. (2012) compared healthy versus mobility-limited older adults, using a short physical performance battery test (SPPB). The test included gait speed, balance and strength and 
is recognized as a functionality test to diagnose sarcopenia (Cruz-Jentoft, et al., 2010). Age was significantly greater for mobility-limited older participants $(77.8 \pm 5$ years $)$ in comparison to healthy middle-aged (47.2 \pm 5 years) and healthy older adults ( $74 \pm 4$ years). Mobility-limited older adults had significantly lower SPPB scores (7.94 \pm 1.3$)$ compared to healthy middle-aged $(11.7 \pm 0.5)$ and healthy older adults $(11.0 \pm 0.9)$. The mobility-limited group reached significance for lower total muscle cross sectional area (CSA) compared to the middle-aged group $(-24.9 \%)$ and healthy older group $(-13.1 \%)$. Moreover, the mobility-limited group showed significant differences in normal density muscle CSA with higher fat deposits in muscle tissue in comparison to the other groups. During their study, Reid, et al. (2012) exemplified some of the typical differences that could be encountered between younger and older adults, especially, when mobility is limited. However, they did not consider history of activity for any of their subjects. Thus, it is hard to speculate, if the mobility challenges for the inactive group were muscle-loss related, or if the muscle and strength loss were based on a history of lack of mobility in their younger years.

During a similar study, Clark, et al. (2010) measured EMG activity in leg muscles in older, healthy adults (OH), older limited-activity adults (OLA) and middle aged adults (MA). The slope of the normalized quadriceps activation was significantly higher in $\mathrm{OH}$ compared to OLA $(p=.03)$. MA had a higher activity with borderline significance compared to OLA $(p=$ .05). Clark et al (2010) infer their findings do not imply impaired voluntary neuromuscular activation is a consequence of age but a derived pathology in the neuromuscular system that could result in mobility disability in some subjects.

Sarcopenia is typically accompanied by a reduction of the basal metabolic rate and less energy expenditure during exercise, along with increased body fat, dyslipidemia, and reduced 
insulin sensitivity (Cruz-Jentoft, Landi, Topinková, \& Michel, 2010). A loss of power and strength are also expected, in part, due to the reduction of faster muscle fibers, Type II (Reid, et al., 2012). During their study, Reid et al. (2012) recorded the lowest levels of leg extensor power in mobility-limited older adults $(365 \pm 159 \mathrm{~W}$ for males, and $228 \pm 77 \mathrm{~W}$ for females $)$ compared to healthy older adults (640 \pm 146 for males, and $256 \pm 71$ for females $)$ and middle aged adults (724 $\pm 213 \mathrm{~W}$ for males, and $450 \pm 124 \mathrm{~W}$ for females). The mobility-limited adult group showed significantly lower muscle cross sectional area on vastus lateralis, compared to the healthy middle-aged subjects $(-24.9 \%, p<0.001)$ and healthy older group $(-13.1 \%, p=0.02)$. Total intermuscular adipose tissue was also highest for the mobility-limited older adult group (4.6 \pm 2.3 for males, and $3.9 \pm 1.5 \mathrm{~cm}^{2}$ for females $)$, compared to the healthy older group $(3.7 \pm 2.6$ for males, and $2.2 \pm 1.6 \mathrm{~cm}^{2}$ for females $)$ and the healthy middle-aged group $(3.07 \pm 1.6$ for males, and $2.5 \pm 1.7 \mathrm{~cm}^{2}$ for females). Such findings suggest sarcopenia increases with limited physical of activity.

Sarcopenia effects on power production and functionality. The death of motor neurons and changes in muscle structure and architecture, such as a reduction in pennation angle and reduced length of fascicles, are commonly known to reduce strength and power (Hunter et al., 2004). After the age of 50, these changes are accentuated and noticeable, especially in the lower limbs. The capacity of developing force quickly (power) is reduced faster than strength $(3.5 \%$ versus $1.5-2 \%$ per year) from the age of 65 (Skelton, et al. 1994). Unfortunately, power is more important for common daily activities and could prevent falls, supporting faster reaction times for unexpected events. Furthermore, age related differences in power reduction between sexes have been noticed, showing women experience a 20\%-30\% greater reduction in power, compared to males in 65 to 89 year old subjects (Skelton, et al., 1994). 
Caserotti, et al. (2001) measured CON and ECC forces during a countermovement jump in elderly males and females. In support to the findings of Skelton, et al. (1994), Caserotti, et al. (2001) found greater peak acceleration during the ECC phase of a countermovement jump for men $\left(4.9 \pm 1.7 \mathrm{~m}^{\mathrm{s}-2}\right)$ compared to women $\left(4.2 \pm 2.0 \mathrm{~m}^{\mathrm{s}-2}\right)$. In addition, the peak ECC deceleration was higher for men $\left(6.18 \pm 2.47 \mathrm{~m}^{\mathrm{s}-2}\right)$ than for women $\left(5.46 \pm 2.64 \mathrm{~m}^{\mathrm{s}-2}\right)$, demonstrating a greater ability for older men to produce and reduce ECC forces in comparison to older women during aging.

Sarcopenia is characterized by muscle Type II fiber atrophy, necrosis and grouping. As motor units are lost, myofibers go through a denervation and reinnervation process (Reid et al., 2012). The changes in motor units caused by age have a particular effect in lower spinal motor neurons, thus all the fibers innervated by such neurons are affected. In addition, the loss of motor neurons causes the reduction in diameter and the number of motor axons in the ventral root (Lexell, 1997).

Doherty, et al. (1993) used surface EMG by placing an active electrode over the main innervations zone of the biceps brachii and an intramuscular needle electrode to document the reduction of working motor units in older adults. During the study, young and older adults were compared to estimate a reduction in motor units in biceps brachii and brachialis. Results reported a $34 \%$ reduction in maximum action potential amplitude in older adults in comparison to younger $(p<0.001)$. A $33 \%$ reduction in ISO torque was reported for the older group when compared to the younger group $(p<0.05)$. The mean estimated number of motor units in young subjects was $357 \pm 97$, compared to $189 \pm 77$ for older adults. Determined by the peak to peak amplitude, the M-potentials were 34\% lower in the older group, when compared to the younger one. The peak to peak amplitude measured for single motor unit action potentials reflected a $23 \%$ 
larger motor unit size, on average, for the older group. The main factor for strength loss accompanied with age is the loss of motor units, even when considering healthy individuals (Doherty, et al. (1993).

D’Antona, Pellegrino, Carlizzi \& Botinelli (2011) compared fiber phenotype between a normally active, young control group (YCTRL), an elderly control group (CTRL), an elderly endurance trained group (END), an elderly sedentary (SED), and an elderly group characterized by an immobilized leg for 3.5 months (IMM). At least 30 fibers per subject were analyzed. Abundant pure type IIb fibers were found exclusively in the SED, characterized by a limited metabolic capacity. There was a trend towards a decrease in cross sectional area in all fibers for the elderly groups. However, only type I and IIa fibers from SED and type I fibers from CTRL were significantly weaker than fibers from YCTRL. The most pronounced reduction in cross sectional area was found in IMM's fibers. Even though lack of activity results into a shift towards faster phenotype (IIb) and exercise promotes a shift towards the more functional, IIa fibers, there is an apparent preferential denervation of fast motor units specifically between the ages of 60-70 years. However, physical activity seems to play a highly impactful role in the maintenance of functional muscle fibers (D'Antona et al (2007). Thus, the possible distribution or composition of Type I to Type II fibers is a result of the interaction of activity level status and the age related cell apoptosis, varying from individual to individual (Narici \& Maffulli, 2010).

\section{Quality and functionality of muscle in older adults}

Current literature indicates that the quality and functionality of muscle is dependent upon multiple factors besides actual muscle mass (D’Antona, et al., 2007; Cruz-Jentoft, et al., 2010; Reid, et al., 2012). Such factors compromise conduction and include: neuromuscular junction 
alterations, the thinning, distention and sprouting of motor axons at terminal portions, and a reduction of endplates in size, density and number. The previously mentioned mechanisms could be due to an age related increase in oxidative stress (Jang \& Remmen, 2011). The reduced rate of action potentials and impaired blood flow to muscle tissues affect the speed of contraction, limiting movement velocity and torque (Clark, et al., 2010). In addition, myocyte apoptosis affects primarily the number of type II muscle fibers, also affecting velocity of movement. Higher recruiting thresholds require greater neural stimulus to initiate muscle contractions. The presence of inflammation, fat, and collagen infiltration within muscles affects muscle function, as part of the process of muscle cell decay. Motor unit reorganization typically results in the addition of type II fibers onto slower motor units with type I fibers, where the type II fibers start expressing activity as type I (Baumgartner, et al., 1998; Clark, et al., 2010; Evans, 2010; van Kan, 2009).

Structural changes in tendons, ligaments and fascia are also noticed. As tissue becomes stiffer, it loses its structural organization and its capacity to restore homeostasis after stress (Flint, Knight \& Kamen, 2009; Reid, et al., 2012). An increase in collagen fibers in connective tissue has been noticed. Odetti, Borgoglio, \& Rolandi (1992) measured collagen-link fluorescence in subjects ranged from 42 to 78 years of age. Intensity of fluorescence at $385 \mathrm{~nm}$ (upon excitation at $335 \mathrm{~nm}$ ) and $440 \mathrm{~nm}$ (upon excitation at $370 \mathrm{~nm}$ ) increased exponentially with age, $\mathrm{r}=.827, \mathrm{y}=114+\mathrm{e}^{0.038 \mathrm{x}}, p<.001$; and $\mathrm{r}=.905, \mathrm{y}=36+\mathrm{e}^{0.039 \mathrm{x}}, p<0.001$, respectively.

All the previously discussed factors indicate that, with age, muscle quality seems more important than quantity. For instance, the decreased levels of muscle mass, (sarcopenia), compared to the loss of strength and functionality (dynapenia) differs substantially over time, 
and such differences could be related to the level of activity of each individual. Active individuals could preserve functionality levels and muscle quality more so than sedentary ones, aside from muscle mass levels (van Kan, 2009).

As an operational definition, sarcopenia is based on skeletal mass, muscle strength and function, considering qualitative and quantitative data. Two international working groups on sarcopenia combined Delmonico and colleagues' proposal with a muscle performance test, gait speed slower than $1 \mathrm{~m}^{\prime} \mathrm{s}^{-1}$. The Special Interest Group (SIG) on cachexia-anorexia implemented Delmonico and colleagues' definition in combination with poor performance in gait velocity $(<$ $0.8 \mathrm{~ms}-1$ ), while the European Working Group on Sarcopenia in Older People (EWGSOP) utilized an algorithm based on low gait speed $\left(0.8 \mathrm{~ms}^{-1}\right)$ and handgrip strength, $<30 \mathrm{~kg}$ for men and $<20 \mathrm{~kg}$ for women (Cruz-Jentoft, et al., 2010). Both, the SIG and the EWGSOP defined that, when one of the two factors is present, muscle mass would be measured to determine sarcopenia in combination with Baumgartner et al. standards. The cut-off points for skeletal muscle mass index (MMI) are $7.26 \mathrm{~kg} / \mathrm{m}^{2}$ for men and $5.5 \mathrm{~kg} / \mathrm{m}^{2}$ for women. (Cruz-Jentoft, et al., 2010). Since gait speed is considered a highly important factor to measure functionality and is a reflection of health (Cruz-Jentoft, et al. 2010; van Kan, 2009), it has become a good indicator of wellness in older adults.

Based on the factors measured when considering sarcopenia, the operational definition is more reliably based on the consideration of MMI and functionality, rather than only MMI. Muscle plays an important metabolic role in homeostasis, as it supports glucose metabolism and reduces insulin resistance (Evans, 2010). 
During the third national health and nutrition examination survey, Srikanthan \& Karlamangla (2011) estimated the body composition and analyzed fasting blood samples for serum insulin and plasma glucose for 13,644 subjects. Skeletal muscle mass was estimated using the equation of Janssen, Heymsfield, Baumgartner, \& Ross (2000): Skeletal muscle mass = $\left[0.401 X\left(\right.\right.$ height $^{2} /$ body impedance $)+(3.825 X$ sex $)+(0.071 X$ age $\left.)\right]+5.102$, with height in centimeters, body impedance in ohms, sex coded as 1 for men and 0 for women, and age in years. The results demonstrated each $1 \mathrm{~kg} / \mathrm{m}^{2}$ increment in muscle mass index was associated with $4 \%$ relative reduction in insulin resistance, $0.3 \%$ relative reduction in glycosylated hemoglobin, and 9\% relative reduction in pre-diabetes or overt diabetes prevalence (Srikanthan \& Karlamangla, 2011). Hence, as sarcopenia (muscle loss) and dynapenia (strength loss) start their progress, these conditions could lead to a loss in functionality, as well as the development of further symptoms, such as cachexia or insulin resistance.

\section{Regular resistance training effects in older adults}

Physical activity is effective in the maintenance of mental and physical health (Haskell, et al., 2007). Specifically, resistance training (RT) plays an important role in maintaining physical abilities, such as muscle strength and hypertrophy (Bamman, et al., 2003; Shariff, Thomas, Donley, Gilleland, \& Bonner, 2012). Bamman, et al. (2003) measured hypertrophy in older men $(n=9,69 \pm 2$ years $)$ and women $(n=5,66 \pm 1$ years $)$. Subjects were trained with whole body resistance, progressive training sessions 3 days a week at 65\%-80\% 1RM for 26 weeks. Results showed increased free-fat mass (men $2.6 \mathrm{~kg}$; women $1.7 \mathrm{~kg}$ ) with a statistically significant reduction in body fat (from $23.3 \pm 1.9 \%$ to $20.4 \pm 2.1 \%$ for men, and from $40.9 \pm 5.3 \%$ to $37.8 \pm$ $5.7 \%$ for women). Participants experienced increased type IIx myofiber area distribution while MHCIIx distribution decreased significantly with RT. The area distribution of type IIa myofibers 
increased with significance in both groups. IIa myofibers are known for higher functionality, as they are a hybrid fiber, with greater aerobic capacity than the IIx fibers.

Shariff, Thomas, Donley, Gilleland, \& Bonner (2011) conducted a case study. The subject was a 46 year-old woman diagnosed with cachexia, a typical condition accompanied with sarcopenia. Apparently, this study was one of the first ones using RT to treat cachexia. The intervention consisted of 16 weeks with 3 RT sessions per week. The RT sessions were considered whole-body for each day. RT resulted in an increase on knee extensor strength by $13.6 \%$ and time to fatigue during graded treadmill exercise increased from 15.30 to $19.30 \mathrm{~min}$, for a $26.1 \%$ improvement. The average muscle fiber cross-sectional area increased by $49.7 \%$ (4634.8 $\mu \mathrm{m}^{2}$ before training, versus $6938.6 \mu \mathrm{m}^{2}$, after training). Muscle nuclei increased from 0.08 to 0.12 nuclei $/ \mu \mathrm{m}^{2}$. Furthermore, a slight decrease $(1.6 \%)$ in the number of apoptotic muscle nuclei after resistance training was noticed. These findings, demonstrate the potential of RT in older adults, not only as a tool to maintain muscle mass, but even to treat sarcopenia or cachexia (Sharif, et al., 2011).

Active stretching prior to resistance exercises could be advantageous, capitalizing on the elevated passive stiffness of muscles in older adults. The known effects of residual force enhancement could be advantageous during training, as muscles store more energy during stretch, in comparison to less stiff muscles in younger populations (Ochala, et al. 2006; Power, et al. 2012). For example, during human locomotion, hip flexors absorb about $40 \%$ of the eccentric work performed during hip extension, producing about half of the net work done during hip flexion passively. Hip flexors capitalize on the elastic energy accumulated during the recent active stretch of the same muscles (Whittington, Silder, Heiderscheit, \& Thelen, 2008). 


\section{Eccentric resistance training in older adults}

Eccentric muscle action (ECC) resistance training (RT) has shown superior muscle strength and hypertrophy adaptations in older adults in comparison to CON, improving functionality and controlling sarcopenia (Lastayo, Pierotti, Pifer, Hoppeler, \& Lindstedt, 2003). For their experiment, Lastayo, et al. (2003) measured isometric strength (ISO) and vastus lateralis hypertrophy adaptations in older adults diagnosed with sarcopenia. Subjects were divided in two groups (ECC and CON). The designated ECC group exercised using a recumbent, ECC cycling ergometer, which allows for the subject to pedal backwards, while working eccentrically. The CON group exercised using traditional weight bearing lower body exercises. After 11 weeks, the ECC group demonstrated greater strength gains; improving from a pretraining mean of $48.8 \pm 6.07 \mathrm{~N}$ to $78.1 \pm 8.78 \mathrm{~N}$, post-training. The traditional group improved from $45.5 \pm 5.48 \mathrm{~N}$ to $52.5 \pm 4.30 \mathrm{~N}$. The strength improvements were significant only for ECC $(p=0.001)$. When measuring vastus lateralis hypertrophy, the ECC group improved from $3295 \pm$ $366 \mu \mathrm{m}^{2}$ to $5273 \pm 963.5 \mu \mathrm{m}^{2}$, while the traditional group reported gains from $2999 \pm 313 \mu \mathrm{m}^{2}$ to $4218 \pm 367 \mu \mathrm{m}^{2}$. The ECC group was superior in functionality, as well. During performance tests, only ECC subjects showed significant $(p<0.05)$ improvement. ECC improved by $7 \%$ on the Berg balance scale and $21 \%$ in stair decent time, progressing from a high to a low fall risk. The traditional group did not improve enough to cross the fall-risk threshold. Their improvements were not significant for balance $(5 \%)(p=0.22)$ and stair descent time $(7 \%)(p=$ 0.56) (Lastayo, et al. 2003).

Raj, Bird, Westfold, \& Shield (2011) found eccentric-biased training (ECCB) more effective than conventional (CONV), when training older adults. The ECCB group performed 
the designated exercises using both limbs during the concentric phase and only one limb during ECC. Limbs were alternated during ECC, for a total of 5 repetitions for each limb, for each set. The total work was matched for both groups: the CONV used 75\% 1RM, in comparison to 50\% 1RM for the ECCB group. After 16 weeks of training, both groups significantly improved 1RM for leg extension ( $\triangle 23-35 \%)$. ECCB had significant improvements for isometric and concentric torque at the highest velocities tested of $240^{\circ} \mathrm{s}^{-1}$ and $360^{\circ} \mathrm{s}^{-1}(\Delta 6-11 \%)$, in comparison to improvements $(\Delta 7-8 \%)$ in slow velocities $\left(60^{\circ} \mathrm{s}^{-1}\right.$ and $120^{\circ} \mathrm{s}^{-1}$ respectively) for CONV. Vastus lateralis cross sectional area was superior for $\operatorname{ECCB}(\Delta 5 \%, p<0.05)$ and did not show significance for CONV. Power stair climb $(\Delta 5 \%)$ was significantly superior for ECCB. Timed up and go $(\Delta 5 \%)$, stair descent $(\Delta 4 \%)$ and vertical jump $(\Delta 7 \%)$ improved significantly in CONV. In terms of functionality, ECCB was able to increase torque at high contraction velocities, demonstrating an improved capability of power production, which is useful for reactive strength in older adults (e.g., fall prevention).

As suggested by Bean, et al. (2002), leg power is a vital component of functionality in older adults, predicting $15-30 \%$ of the variance in physical performance for gait, stair climb time, and timed up and go. Special considerations should be taken when choosing the ideal resistance training modality to maximize power adaptations for elderly subjects.

Leszczak, Olson, Stafford, \& Di Brezzo (2013) compared the effects of high velocity training (HV) with ECC training. During HV, the subjects emphasized on making the CON phase as fast as possible, while the ECC was a 2-3 seconds phase. For the ECC training group, the intensity was $75 \%$ of $1 \mathrm{RM}$. The CON phase was assisted by a trainer, with a controlled, 1-2 second duration lift, followed by a 3-5 second ECC phase, unassisted. After 8 weeks of training, the results of the study demonstrated very similar effects, suggesting that ECC training enhances 
strength similarly to HV. Even though there were no significant differences between groups, the combined walking time for both groups before treatment was $4.47 \mathrm{~s}$, and $4.20 \mathrm{~s}$, after training. The up and go test was $5.82 \mathrm{~s}$ before and $5.52 \mathrm{~s}$ after, the chair stand test improved from 14.24 stands before training to 16.61 after training. In addition, the combined weight lifted in leg press increased from $329.21 \mathrm{lbs}$ before intervention and $472.58 \mathrm{lbs}$ after. For the seated leg curl, 75.89 lbs were recorded before training and $100.84 \mathrm{lbs}$ after. The combined seated leg extension was 61.47 lbs before intervention and improved to $88.57 \mathrm{lbs}$, after training. Neither group demonstrated superior results.

ECC training seems to be a viable option when training older adults. ECC training appears advantageous for its strength gains, and improved muscle mass adaptations, while enhancing speed of contraction. The strength and muscle mass gains may be partially attributed to the increased residual force enhancement capabilities in older adults, which capitalize on the increased muscle and tendon stiffness.

\section{The Biodex reliability}

Strength can be measured through different methods, including manual testing and hand held dynamometry, however such methods are limited by the expertise and strength of the test administrator and could affect results. The Biodex is an isokinetic strength assessment tool that is commonly used in clinical practice and research. It is safe and relatively easy to operate. It is not invasive and is fairly comfortable for the tested subject. More importantly, the Biodex is widely

used in research for its testing reproducibility (Hartmann, Knols, Murer, \& de Bruin, 2009). The Biodex includes a lever that is placed perpendicularly on the lower leg of the subject and offers resistance depending on the chosen settings. The resistance provided by the Biodex is used to 
measure strength in terms of torque (moment of force causing rotation about an axis) during different muscle actions. CON torque, as the leg moves into extension, ECC torque, as the leg moves into flexion, or ISO torque, as the leg produces force while pushing on the lever, without an apparent change in the knee angle.

Hartmann, et al. 2009 tested the reliability of the Biodex by conducting a leg strength test in two separate sessions, separated by 5-10 days and conducted at approximately the same tome of the day. Twenty four older adults ( $\geq 65$ years) were tested twice during the first session (t1 and $\mathrm{t} 2$ ), with 1 hour rest between measures and conducted by two different raters. A third strength test (t3) was taken after 5-10 days. To measure the inter-rater reliability, one of the first

two tests ( $\mathrm{t} 1$ or $\mathrm{t} 2)$ was randomly chosen and compared to the second test (t3). Isokinetic muscle actions of the leg extensors were recorded at $60 \%$ s and $120 \%$ s to mimic most daily activities. The intra-class correlation coefficients of the isokinetic measures ranged from 0.87 to 0.94 for leg extension tests at different velocities, with a standard error of measurement between 8.0 and $9.3 \%$ demonstrating very good reliability.

\section{Summary}

The natural process of aging includes the death of motoneurons, primarily affecting the motor units responsible for fast muscle contraction. Muscle decay takes place and overall function is affected. However, physical activity and training may manage such changes, supporting overall health, strength and functionality, while reducing the effects of sarcopenia. The natural increased stiffness in aging muscle fibers improve their capacity of accumulating passive energy during the lengthening of the fibers, allowing an enhanced capacity of producing eccentric forces, in comparison to younger populations. Considering the previous factors, the purpose of this study is to measure leg extensor ISO, CON and ECC torque in trained and 
untrained older adults, comparing ECC to ISO. The findings could be helpful to better understand the effects of RT in strength in older adults for future reference and emphasize the possible implications of ECC training, to promote functionality and control sarcopenia, regardless of the known capacity of maintaining of ECC during old age. 


\section{Chapter III}

\section{Methods and Procedures}

\section{Introduction}

This study was designed to measure the difference in leg extensor peak concentric $(\mathrm{CON})$ torque, isometric (ISO) torque and eccentric (ECC) torque, between trained and untrained older adults. ECC was compared to ISO as a ratio (ECC: ISO). Within this chapter, a description of the study subjects is included, along with the basis of study design, a description of the methods and the equipment used, as well as the data processing and analysis approach to this study.

\section{Description of Study Subjects}

Twenty, injury-free, older men and women (over 60 years of age) were recruited into two groups: trained $(\mathrm{T})$ and untrained $(\mathrm{U})$. The T group was formed by subjects who have participated in the mature adult resistance training program for at least 6 months at Western Washington University, Bellingham Senior's Center or Blaine Senior's Center, with a frequency of 2-3 times per week, in the last 6 months. The training program included 8-10 exercises, with 10-15 repetitions each. Any individuals who trained less than two sessions in a week were excluded from the $\mathrm{T}$ group and enrolled in the $\mathrm{U}$. The $\mathrm{U}$ group consisted of older individuals who have not participated in any resistance training program at least twice per week in the last 6 months.

\section{Design of Study}

This study was a two group comparison, ex post facto. An independent sample t-test was used to compare mean values of leg extensor peak CON, ECC and ISO torque. The ratio of ECC: 
ISO was calculated, considering ISO as a basal level of strength. The ratio could help illustrate the maintenance of ECC, in relationship to basal strength in trained and untrained older adults. The effect size was determined for each variable. Both, absolute and relative torques were considered for analysis. Only the dominant leg was tested.

\section{Data collection procedures}

All data collections took place in the Biomechanics Laboratory at Western Washington University. Upon arrival to the laboratory, the informed consent was explained to the subject before instructing her/him to read it. The document included an explanation of the procedures, risks and benefits of their participation in the experiment, as well as the purpose of the study (see Appendix A). When consent was obtained, any possible questions were answered to ensure clarification. Before testing, age, sex, recent resistance training experience, and frequency of training were recorded. Height and weight were measured and recorded, using a stadiometer and an analog scale. Leg dominance was determined by asking subjects to kick a soft, 7 inch, foam ball. The kicking leg was determined as the dominant leg (Hartmann, Knols, Murer, \& de Bruin, 2009).

Instrumentation. A Biodex (Biodex, Shirley, NY) isokinetic dynamometer was used to measure instantaneous maximum torque at various preset constant angular velocities. For the purposes of this study, leg extensor ISO, CON and ECC torques were measured. The Biodex was calibrated according to the manufacturer's specifications before each test session. Subjects were seated with the trunk vertical and thigh fixed at about $80^{\circ}$ hip angle. Velcro straps were secured tightly across thorax, pelvis and distal thigh. Values for peak ISO at $50^{\circ}$ of knee flexion were recorded, corresponding to the middle of the range of motion (Babault, Pousson, Ballay, \& Van Hoecke, 
2001). In addition, isokinetic muscle actions were performed at an angular velocity of $120 \% \mathrm{~s}$ during concentric and eccentric load of leg extensors to mimic real life events, such as sitting, lowering a bag of groceries, or even resisting a fall after tripping. (Hartmann, et al., 2009). The range of motion was measured from $20^{\circ}$ to $80^{\circ}$ of knee flexion to avoid extreme soft tissue stress. Peak CON, ECC and ISO were measured and recorded for each subject.

\section{Description of technique and procedures}

Each subject was instructed to perform a general warm-up for 5 minutes using a cycle ergometer with no resistance added. Once the general warm-up was completed, the subject was briefly introduced to the Biodex (Biodex, Shirley, NY) and its function in the study. All tests were performed exclusively on the dominant leg. The order for the three testing conditions (ISO, CON and ECC) was randomized by having the subject blindly select a colored marble out of a bag, to define which test was performed first. A second marble selection determined the second test and the third test was defined by the color of the remaining marble found in the bag. The assigned colors were blue for CON, white for ISO and red for ECC. The subject was instructed to sit on the dynamometer's chair as proper adjustments were made, ensuring the center of rotation of the shaft of the dynamometer was in alignment with the lateral femoral epicondyle of the dominant leg. For that purpose, the back of the seat was adjusted and the length of the dynamometer's arm was properly fitted to the length of the participant's right shank. The shank pad was positioned on the distal portion of the tibia Subject was positioned sitting with a hip angle at about $80^{\circ}$. The participant was stabilized with two shoulder straps, a waist strap, and a thigh strap, to reduce extraneous movements. Once in proper position, each subject was instructed to perform a warm-up, consisting of 3 sub-maximal contractions, at $60-70 \%$ of 
isometric, maximum voluntary contraction (MVC) of the leg extensors, followed by a 30 second rest at the original starting position of $50^{\circ}$ of knee flexion. Based on the randomly selected test order, three ISO, ECC and CON MVC of the dominant thigh were recorded. Every test for each condition was followed by 2 minutes of rest. For the ISO test, the subject pushed into extension against the dynamometer, starting at $50^{\circ}$ of knee flexion, with duration of 5 seconds per contraction, allowing 2 minutes of rest between repetitions. Only the maximum torque value was recorded. For the isokinetic tests, three maximal, ECC and $\mathrm{CON}$ were recorded at an angular velocity of $120^{\circ} / \mathrm{s}$, during ECC or CON load of leg extensors. The range of motion was from $20^{\circ}$ to $80^{\circ}$ of knee flexion, as the subject was instructed to maximally resist the dynamometer as it moved towards leg flexion during ECC, and as subject pushed against the dynamometer into leg extension during CON. A two minute resting period was allowed between trials. All three trials for a given condition were performed before moving on to the next condition. After the completion of three attempts for each of the three conditions, each subject was instructed to perform a cool down for 5 minutes on cycle ergometer, at an easy pace, with no resistance added.

\section{Data Analysis}

Only the maximum peak torque value for each condition was considered for every subject. Peak ISO, CON and ECC torques were analyzed and normalized to each subject's weight. A ratio of ECC: ISO was calculated by dividing the maximum ECC value by the maximum ISO value for each subject, for both groups. The groups were compared to determine differences between trained and untrained groups.

The data was organized and statistically analyzed by implementing IBM SPSS Statistics for Windows, Version 21.0. Armonk, NY: IBM Corp. and Microsoft (2003). Microsoft Excel, 
Redmond, Washington: Microsoft. software. Descriptive statistics were calculated for CON,

ECC, ISO, and ECC: ISO for each group. A t-test was used to determine significant differences between the trained and untrained groups for each condition. Cohen's d effect size was calculated to measure the standardized difference between means across groups. 


\section{Chapter IV}

\section{Results and Discussion}

\section{Introduction}

Three maximum efforts of each, isometric (ISO), eccentric (ECC), and concentric (CON) leg extensor torque were measured in adults over 60 years of age, on the dominant leg. The order of the tests was randomized and only the peak torque values were considered for analysis. It was hypothesized that, there would be no significant difference in ECC torque, CON torque, and ISO torque, or ECC: ISO ratio, between trained and untrained older adults. Subjects were divided into two groups: trained (T) and untrained (U). The qualifying criteria for the $\mathrm{T}$ group required that each subject had participated consistently, at least twice a week in resistance training exercises for the last six months. Any individual who had not participated in resistance training exercises, at least twice per week in the last six months was assigned to the $U$ group. Relative torque was calculated for each subject, using ISO as a basal marker and divided by their body weight in kilograms. The ECC: ISO ratio was also calculated. The experimental design included a t-test to determine possible differences between groups for each variable considering absolute and relative values. A description of the subjects' characteristics is reported in the subsequent section. Further, the experimental results are presented, accompanied by the corresponding analyses and discussion.

\section{Subject characteristics}

Twenty subjects ( 12 men, 8 women) aged 60 to 81 years $(70 \pm 6.1$ years ) volunteered for this study. The average weight was $80.54 \pm 16.44 \mathrm{~kg}$, with an average height of $1.69 \pm 0.082 \mathrm{~m}$. 
The subjects were recruited from the Mature Adult Training Program, at Western Washington University, as well as the Bellingham Senior's Center and the Blaine Senior's Center. All subjects were physically active and were granted physician's clearance to perform maximum leg strength testing prior to their participation. Subjects in the T group had been resistance training for at least, the last six months, a minimum of two times per week. Most of the subjects in the U group were also resistance training, but could not fit in the T criteria due to a short length of recent training history (less than 6 months), or a training frequency lower than twice per week, on average. None of the subjects had neuromuscular disorders nor had a history of knee injury. More importantly, all subjects were cleared by a physician for maximum leg extension strength testing. The dominant leg was determined by asking each subject to kick a foam ball. The preferred, kicking leg was tested. Nineteen out of twenty subjects demonstrated right leg dominance. Table 1 illustrates subjects' characteristics by group:

\section{Table 1. Subjects Characteristics}

\begin{tabular}{|lcccc|}
\hline & \multicolumn{2}{c}{ Trained (T) Group } & \multicolumn{2}{c|}{ Untrained (U) Group } \\
(6 males, 4 females, each group) & Mean & SD & Mean & SD \\
Height $(\mathbf{m})$ & 1.69 & 0.08 & 1.70 & 0.09 \\
Weight $(\mathbf{k g})$ & 77.94 & 16.97 & 83.15 & 16.36 \\
Age (yrs) & 69 & 8 & 71 & 4 \\
\hline
\end{tabular}




\section{Results}

The mean values and standard deviations for each group are illustrated on Table 2. Leg extension peak values (Pk) of ISO torque, ECC torque and CON torque along with ECC: ISO and relative (Rel) torque values for each condition are included in the following table:

Table 2. Torque and ratio values of trained and untrained subjects

\begin{tabular}{|l|c|c|c|c|}
\hline & \multicolumn{2}{|c|}{ Trained (T) Group } & \multicolumn{2}{c|}{ Untrained (U) Group } \\
\hline Variable & Mean & SD & Mean & SD \\
\hline Pk ISO (Nm) & 183.8 & 36.4 & 137.1 & 35.2 \\
\hline Pk ECC (Nm) & 226.4 & 52.0 & 198.7 & 45.1 \\
\hline Pk CON (Nm) & 119.5 & 20.4 & 101.1 & 25.0 \\
\hline ECC: ISO & 1.234 & 0.183 & 1.479 & 0.269 \\
\hline Rel ISO (Nm/kg) & 2.403 & 0.453 & 1.666 & 0.357 \\
\hline Rel ECC (Nm/kg) & 2.969 & 0.676 & 2.476 & 0.810 \\
\hline Rel CON (Nm/kg) & 1.562 & 0.238 & 1.241 & 0.316 \\
\hline
\end{tabular}

Differences were observed in each plot while testing subjects. The following figure (Fig. 1) depicts an actual plot displayed by the Biodex after measuring one repetition of a leg extension peak torque in $\mathrm{Nm}$. 


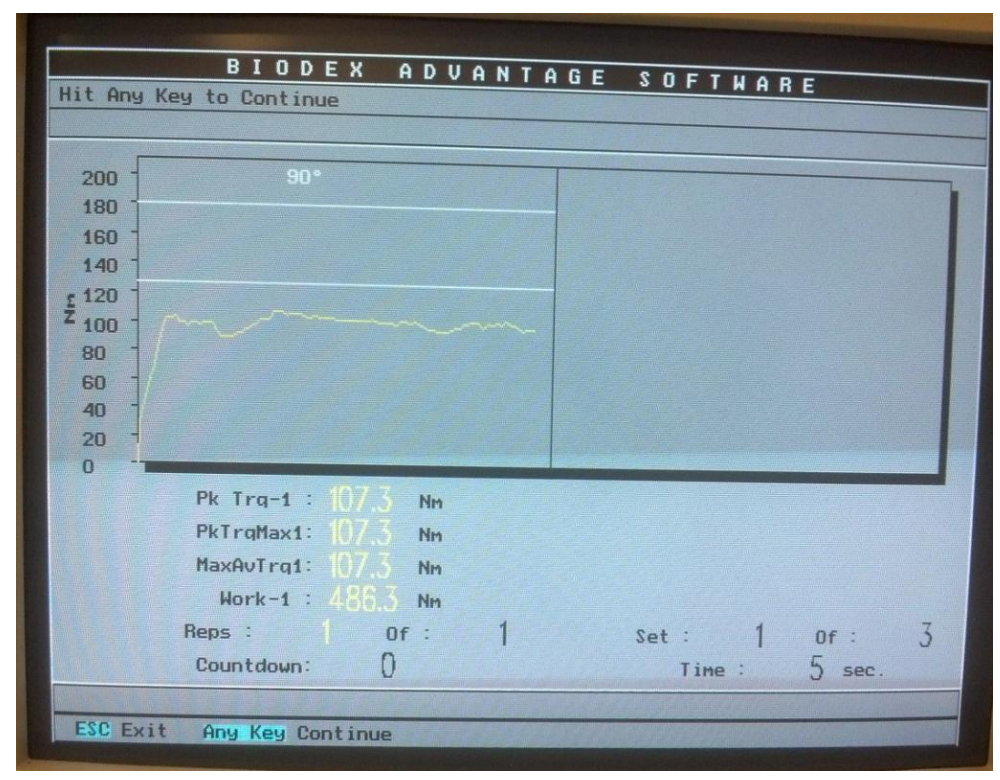

Fig. 1. Biodex plot representing leg torque during ISO testing

The T group $(183.3 \pm 36.4 \mathrm{Nm})$ demonstrated significantly higher ISO than the U group $(137.1 \pm 35.2 \mathrm{Nm})(\mathrm{t}(\mathrm{df})=2.913(18), p=0.009)$, with a large effect size $(\mathrm{d}=1.30)$. Pk ECC was greater for $\mathrm{T}(226.4 \pm 51.9 \mathrm{Nm})$ compared to $\mathrm{U}(198.7 \pm 45.1 \mathrm{Nm})$, but the difference did not reach significance $(\mathrm{t}(\mathrm{df})=1.271(18), p=0.220)$, with a moderate effect size $(\mathrm{d}=0.57)$. For Pk CON, T demonstrated greater results $(119.5 \pm 20.4 \mathrm{Nm})$ when compared to $\mathrm{U}(101.1 \pm 25.0$ $\mathrm{Nm}$ ), but the difference was not significant ( $(\mathrm{df})=1.804(18), p=0.088$ ) with a large effect size $(\mathrm{d}=0.81)$. In an attempt to illustrate the differences in basal strength between groups, and measure the capacity of maintaining eccentric strength regardless of training status, an ECC: ISO ratio was calculated. The results showed a significant $(\mathrm{t}(\mathrm{df})=-2.375(18), p=0.029)$ difference in the ECC: ISO between groups, with a lower ratio for T $(\mathrm{ECC}$ : ISO $=1.234 \pm 0.183)$ in comparison to $\mathrm{U}(\mathrm{ECC}$ : ISO $=1.479 \pm 0.269)$, with a large effect size $(\mathrm{d}=1.07)$. 
When considering relative (Rel) torque values, Rel ISO was significantly $(\mathrm{t}(\mathrm{df})=4.043$ (18), $p=0.001)$ superior for $\mathrm{T}(2.367 \pm 0.474 \mathrm{Nm} / \mathrm{Kg})$ when compared to $\mathrm{U}(1.666 \pm 0.357$

$\mathrm{Nm} / \mathrm{Kg})$. Rel CON was significantly higher $(\mathrm{t}(\mathrm{df})=2.571(18), p=0.019)$ for $\mathrm{T}(1.562 \pm 0.237$

$\mathrm{Nm} / \mathrm{Kg})$ with a large effect size $(d=1.149)$ in comparison to $\mathrm{U}(1.241 \pm 0.316 \mathrm{Nm} / \mathrm{Kg})$. Rel

ECC was greater for $\mathrm{T}(2.969 \pm 0.676 \mathrm{Nm} / \mathrm{Kg})$ but did not reach significance $(\mathrm{t}(\mathrm{df})=1.478(18)$, $p=0.157)$, with a moderate effect size $(\mathrm{d}=0.66)$, in comparison to $\mathrm{U}(2.476 \pm 0.810 \mathrm{Nm} / \mathrm{Kg})$.

The following table (Table 3) depicts results, with effect size and p-values (table 3).

Table 3. Results including means, standard deviation, p-value and Cohen's d effect size

\begin{tabular}{|c|c|c|c|c|c|}
\hline Group & Variable & Mean & Std Dev & p-value & $\begin{array}{l}\text { Cohen's d } \\
\text { Effect Size }\end{array}$ \\
\hline$T$ & Pk ISO (Nm) & 183.8 & 36.4 & $P=0.009$ & 1.3 \\
\hline$U$ & $\mathrm{Pk}$ ISO (Nm) & 137.1 & 35.2 & Significant & Large \\
\hline $\mathrm{T}$ & $\mathrm{Pk}$ ECC $(\mathrm{Nm})$ & 226.4 & 51.9 & $P=0.220$ & 0.6 \\
\hline U & $\mathrm{Pk}$ ECC (Nm) & 198.7 & 45.1 & Not significant & Moderate \\
\hline $\mathrm{T}$ & Pk CON (Nm) & 119.5 & 20.4 & $P=0.088$ & 0.8 \\
\hline $\mathrm{U}$ & $\mathrm{Pk}$ CON (Nm) & 101.1 & 25.0 & Not significant & Large \\
\hline $\mathrm{T}$ & ECC:ISO & 1.234 & 0.183 & $P=0.029$ & 1.1 \\
\hline$U$ & ECC:ISO & 1.479 & 0.270 & Significant & Large \\
\hline $\mathrm{T}$ & Rel ISO (Nm/kg) & 2.403 & 0.453 & $P=0.001$ & 1.8 \\
\hline$U$ & Rel ISO (Nm/kg) & 1.666 & 0.357 & Significant & Large \\
\hline $\mathrm{T}$ & Rel ECC (Nm/kg) & 2.969 & 0.676 & $P=0.157$ & 0.7 \\
\hline$U$ & Rel ECC (Nm/kg) & 2.476 & 0.810 & Not significant & Moderate \\
\hline $\mathrm{T}$ & Rel CON (Nm/kg) & 1.562 & 0.237 & $P=0.019$ & 1.1 \\
\hline$U$ & Rel CON (Nm/kg) & 1.241 & 0.316 & Significant & Large \\
\hline
\end{tabular}

The subsequent figures (Fig. 2 and Fig. 3) illustrate the statistical findings, comparing results across groups. 


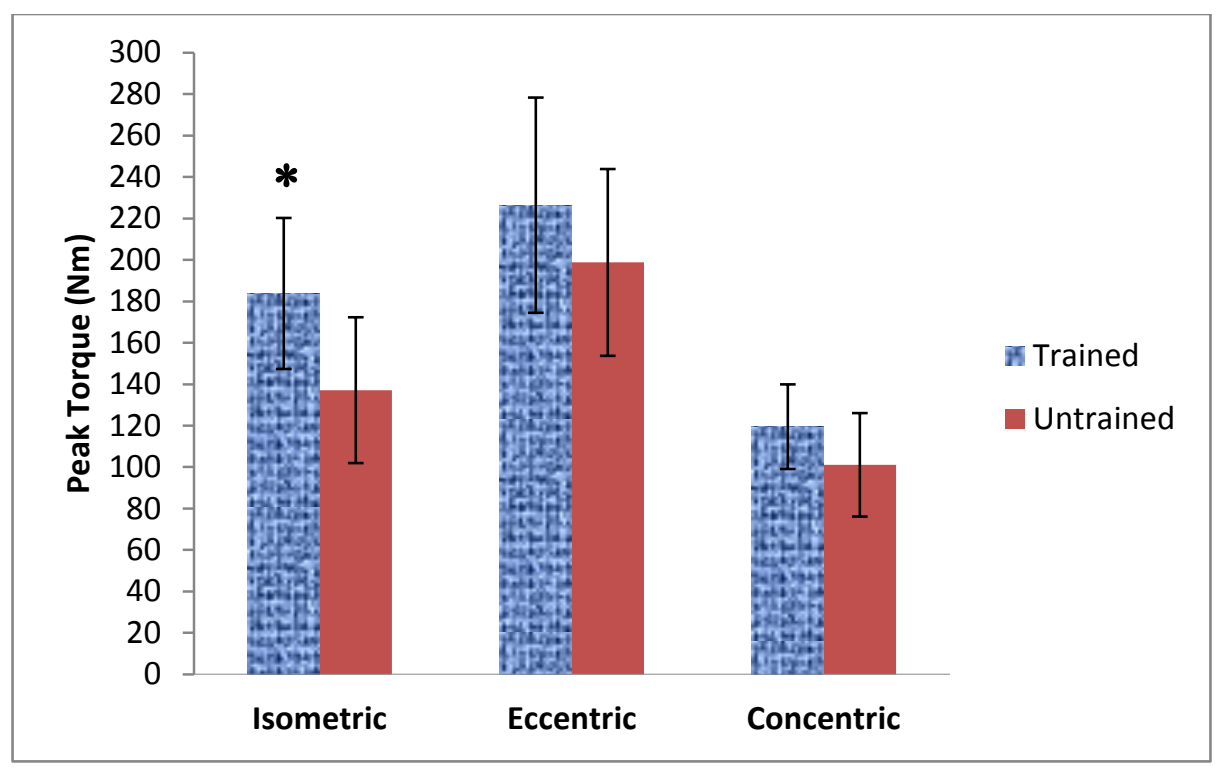

Fig. 2. Leg Extension absolute peak torque values * $p<0.05$

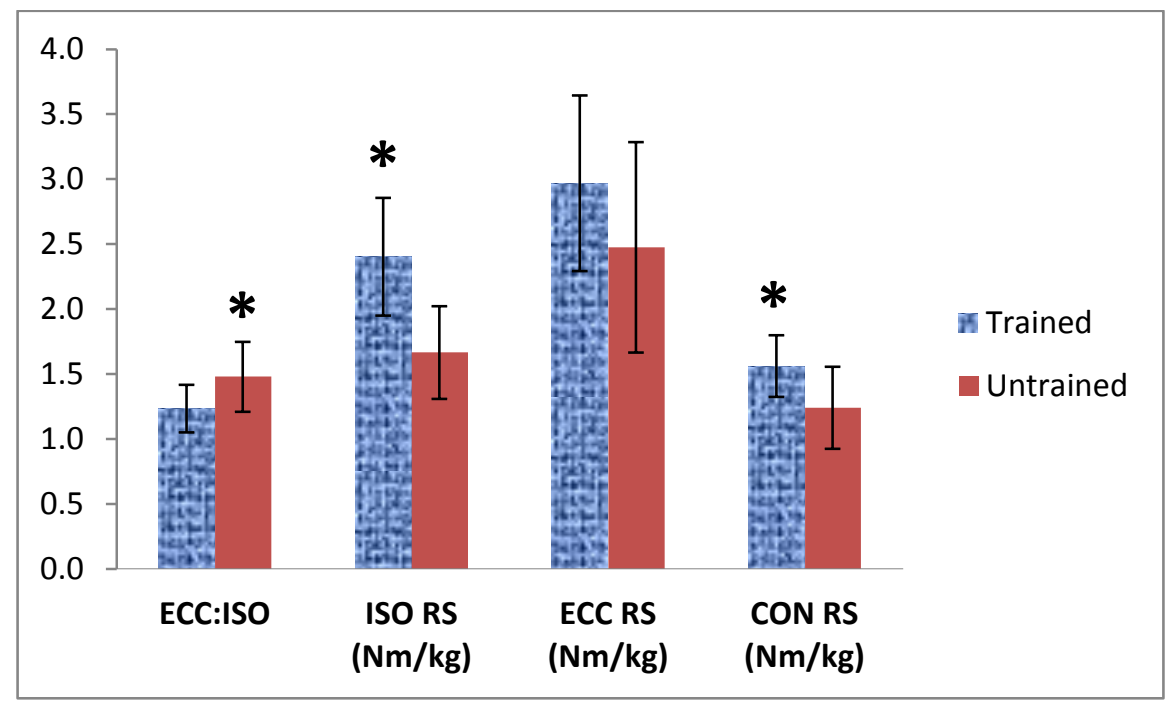

Fig. 3 Eccentric to isometric ratio and ISO, ECC and CON relative strength (RS)

$* \mathrm{p}<0.05$ 


\section{Discussion}

The present study had the purpose of investigating the possible differences in leg extensor torque between resistance trained $(\mathrm{T})$ and untrained $(\mathrm{U})$ older adults. Although prior research demonstrates ECC strength is well maintained in older adults, none has looked at the differences between $\mathrm{T}$ and $\mathrm{U}$ older adults. The null hypothesis was rejected, as the primary findings revealed significantly greater ECC to ISO ratio (ECC: ISO) for the U group, when compared to the T group. However, no significant differences for ECC were found. The T group was significantly superior to the U group for ISO, which is recognized as a basal measure of strength. When comparing relative (Rel) $\mathrm{CON}$, the superiority of the T group reached significance versus the $\mathrm{U}$ group. Relative torque is considered a more precise way to compare levels of strength, for it considers the capacity of producing force relative to body mass $(\mathrm{Nm} / \mathrm{kg})$ (Lindle, et al. 1997). This study provides evidence to support that ECC is well maintained in older adults, regardless of training status. The higher ratio of ECC to ISO for the U group suggests that even older adults who do not exercise regularly and who have lower levels of basal strength (ISO) are able to maintain ECC strength. The results are not conclusive when considering differences in $\mathrm{CON}$ in $\mathrm{T}$ and $\mathrm{U}$ older adults.

The ECC: ISO was significantly larger for U (ECC: ISO $=1.479 \pm 0.270)$, with a lower ratio for $\mathrm{T}(\mathrm{ECC}$ : $\mathrm{ISO}=1.234 \pm 0.183)$. Considering that $\mathrm{ISO}$ is recognized as a basal level of strength, a greater ECC: ISO value suggests that, even though the U group was considered less strong than the T group (because of its proportionally lower ISO), the non-significant differences in ECC made the ratio greater for the U group. The difference is explained by the larger dividend (ECC) in proportion to the divisor (ISO) when compared to a more equally balanced ratio for the T group. 
In congruence with the findings in this study, Klass, et. al (2005) demonstrated the maintenance of ECC strength in older adults, by comparing younger and older subjects. Klass, et al. (2005) found that even though the younger group produced overall greater dorsiflexor ISO $(20.5 \%)$ and CON (38.6\%), the superiority of the younger group was considerably lower for ECC (6.5\%). Such findings indicate that ECC is maintained for longer with aging.

During the present study, training status was not a highly determinant factor when comparing ECC between groups. No significant difference was found for ECC between T (226.4 $\pm 51.9 \mathrm{Nm})$ and $\mathrm{U}(198.7 \pm 45.1 \mathrm{Nm})$ individuals. The results support the contention that ECC is easier to maintain over ISO, even in those older individuals who do not exercise regularly. In contrast with previous findings (Klass, et al. 2005) CON was not significantly different between groups, with $119.5 \pm 20.4 \mathrm{Nm}$ for the T group and 101.1 $\pm 25.0 \mathrm{Nm}$ for the $\mathrm{U}$ group. The previously mentioned figures suggest $\mathrm{CON}$ is well maintained in older adults. Nonetheless, the evidence for $\mathrm{CON}$ was not clear enough to make a conclusion when the relative CON was significantly higher for $\mathrm{T}(1.562 \pm 0.237 \mathrm{Nm} / \mathrm{Kg})$ in comparison to $\mathrm{U}(1.241 \pm 0.316 \mathrm{Nm} / \mathrm{Kg})$. It is important to mention the difference in body mass between groups was not significant $(\mathrm{p}=$ 0.493), with a mean of $77.94 \pm 16.97 \mathrm{~kg}$ for $\mathrm{T}$ and $83.15 \pm 16.36 \mathrm{~kg}$ for U. However, body composition was not measured.

In previous findings, Pousson, et. al (2001) found significantly greater, relative constant angular torque values, in older adults' arm flexors during ECC $\left(35.5 \pm 7.2 \mathrm{Nm}\right.$, at $120^{\circ} / \mathrm{sec}$, and $35.5 \pm 5.1 \mathrm{Nm}$, at $60 \% / \mathrm{sec})$ in comparison to younger subjects $(63.2 \pm 11 \mathrm{Nm}$, at $120 \% \mathrm{sec}$, and 65.4 $\pm 9.3 \mathrm{Nm}$, at $\left.60^{\circ} / \mathrm{sec}\right)$. Conversely, the older adults recorded significantly lower values $\left(14.7 \pm 4.2 \mathrm{Nm}\right.$, at $120^{\circ} / \mathrm{sec}$, and $8.1 \pm 3.1 \mathrm{Nm}$, at $\left.240^{\circ} / \mathrm{sec}\right)$ during $\mathrm{CON}$, when compared to 
younger counterparts $\left(40.5 \pm 9.1 \mathrm{Nm}\right.$, at $120^{\circ} / \mathrm{sec}$, and $34.8 \pm 9.1 \mathrm{Nm}$, at $\left.240^{\circ} / \mathrm{sec}\right)$. The previous findings support the capability of older adults to maintain ECC. Interestingly, the older subjects in Pousson et al.'s (2001) study were considered sedentary, and could be compared to the U group in the current study. Pousson, et al. (2001) found lower EMG activity during CON and ECC for the older group, when compared to the young, showing greater force production efficiency for the older adults. The relative ECC torque was also greater for the older group, suggesting that the maintenance of ECC at low energy cost could be attributed to the mechanical characteristics in old muscle and connective tissue, regardless of possible challenges in neuromuscular activity. An alternative explanation for the non-significant difference in ECC across groups could be explained by the type of RT and the force-velocity curve. That is, there is a greater capacity of generating forces during ECC compared to CON and ISO. Thus, during regular RT (which was practiced by the T group in this study), the ECC portion of the exercise is typically under loaded, limiting the possible improvements on ECC.

The maintenance of ECC in older adults could be attributed to changes in tissue organization and increased stiffness in extracellular matrix (ECM). Given that the extracellular matrix (ECM) supports most of the passive loads, an increased level of stiffness and reduced range of motion could be directly dependant on ECM status, and could be useful for the maintenance of ECC during old age (Schwartz, 2010).

In a twelve week study comparing ISO, CON and ECC resistance training (RT), Symons, et al. (2005) found that the ECC RT group had the greatest leg extension, ECC improvement (26\%) compared to the CON RT group (10\%). Interestingly, the ISO RT group had almost the same ECC improvement (25\%) as the ECC RT group. These findings exemplify the superior effects of ECC RT and ISO RT over CON RT training in ECC gains. In addition, it is 
important to consider that regular RT emphasizes mostly on CON. Thus, regular RT could be comparable to a CON RT program.

In consideration of previous experimental methods (Pousson, et al., 2001), during this experiment, the speed selected for ECC and CON testing was $120^{\circ} / \mathrm{sec}$; justified by the similarity to the speed of daily life activities, such as sitting, lowering a bag of groceries, or even resisting a fall after tripping. The force-velocity curve indicates that ECC forces increase with speed. However, a maximum voluntary contraction at $120^{\circ} / \mathrm{sec}$ for $\mathrm{CON}$ is more challenging, as force production capability during $\mathrm{CON}$ is inversely proportional to the speed of contraction.

In the present study, only relative CON was significantly $(p=0.019)$ greater for the $\mathrm{T}$ group $(1.562 \pm 0.237 \mathrm{Nm} / \mathrm{Kg})$ in comparison to $\mathrm{U}(1.241 \pm 0.316 \mathrm{Nm} / \mathrm{Kg})$. Mean peak torque for CON was greater for the T group $(119.5 \pm 20.4 \mathrm{Nm})$ compared to the $\mathrm{U}$ group $(101.1 \pm 25.0 \mathrm{Nm})$ but the difference was not significant $(\mathrm{p}=0.088)$. It is possible that relative CON was higher for trained subjects as they were better prepared to produce $\mathrm{CON}$ forces, maybe due to their superior neuromuscular adaptations, previously obtained in response to consistent RT. Those adaptations could include an increase in calcium delivery, greater rate coding, improved neuromuscular efficiency, increased strength and hypertrophy (Bamman, et. al, 2003; Shariff et. al, 2011). For instance, Reeves, Narici, \& Maganaris (2006) found increases of muscle anatomical crosssectional area by $5-17 \%$ after 14 weeks of RT. In addition, RT has been known to reduce the mechanisms of sarcopenia, characterized by the loss of motoneurons, denervation of fast twitch fibers with a possible reinnervation onto slow twitch motor units, and muscle cell apoptosis.

Reeves, Narici, \& Maganaris (2009) reported improvements of 9-37\% in leg extension ISO and CON after 14 weeks of RT in older adults (65-81 years), accompanied by an increase in 
agonist muscle neural drive, with no change in antagonist coactivation. RT is also known to cause changes in fiber type, supporting the genotype IIa, fiber that is more functional than the type IIb in older adults. However, genetic profile and previous activity history could dictate the tendency of some subjects to have certain dominant fiber types. During the present experiment, strength testing performance could have been influenced by fiber phenotype in different subjects.

The absolute values for ISO were significantly in favor of the T group $(183.3 \pm 36.4 \mathrm{Nm})$ compared to the $\mathrm{U}$ group $(137.1 \pm 35.1 \mathrm{Nm})$. The natural process of aging includes changes in muscle and connective tissue, as well as changes in neuromuscular activity leading to reduced strength and power production. Nevertheless, RT is known to improve ISO which is considered a marker of basal strength. The findings by Henwood, Riek, \& Taaffe (2008) may help explain the superiority of the T group in the present study. During their experiment, Henwood et al. (2008) measured leg extension ISO in older adults before and after a 24 week RT program intervention, as all subjects trained twice per week. The results showed an improvement of $23.8 \pm 5.5 \%$ in leg extensor ISO for one group and $29.7 \pm 6.9 \%$ improvement for another. Such evidence supports the results of the present study, where the T group showed a significant superiority in ISO, when compared to the $\mathrm{U}$ group.

Earlier research offers myriad explanations as the possible mechanisms of ECC maintenance. Power, Makrakos, Rice, \& Vandervoort (2013) found and increased residual force enhancement (RFE) capacity in older subjects when compared to younger. RFE is simply explained as: during the lengthening of an active muscle (ECC), the force level measured after the stretch is superior to the isometric force at the equivalent muscle length. This phenomenon 
could take place as a possible combination of passive and active factors influencing ECC strength.

In similar findings, Ochala, et al. (2006) chemically skinned single muscle fibers $(\mathrm{n}=$ 235) from vastus lateralis of six young adults (mean age 31.6) and six older adults (mean age 66.1) and measured maximal ISO and cross sectional area to calculate tension. After applying a quick stretch, an immediate increase in tension occurred, followed by a decrease. Later, a secondary increase in tension was observed. Ochala, et al. (2006) concluded that the limited reduction of $\mathrm{ECC}$, in comparison to ISO and $\mathrm{CON}$, in older adults could be explained by an age dependent maintenance of tension after stretch in muscle fibers. The maintenance of tension following stretch could be interpreted as an increase in stiffness, or increased resistance to stretch.

Pousson, et. al (2001), argued that ECC maintenance is dependent on an increase in connective tissue and collagen-cross linking that augments the number of attachments of sarcomeres with tendons. Such connections could offer a greater mechanical advantage, improving the resistance to stretch, in contribution to an enhancement of passive forces during ECC. Changes in stiffness include passive and active factors. Passive stiffness is mainly derived from connective tissue, such as fascia, ligaments and tendons, and to a minor extent to the spring- like giant protein found in muscle (titin).

Active stiffness refers to voluntary muscle actions (Liu et al., 2006). Liu et al. (2006) and Hortobágyi \& DeVita (2000) state that increased stiffness in older adults is related to the augment of antagonistic muscle coactivity (active stiffness), and could be useful to maintain ECC strength during older age. However, other studies argue that there are no alterations in 
neural activity and the maintenance of ECC depends on mechanical factors. Pousson, et al. (2001) measured ISO, ECC and CON in elbow flexors and did not find significant differences in coactivation between young and old adults. Power, et al. (2013) did not find significant differences in muscle co-activation between old and young adults. Unfortunately, during the present study, stiffness was not measured, so no further conclusions could be made.

It is important to consider that the studies by Power et al. (2013) and Pousson, et al. (2001) measured single joint, open chain movements and encountered no differences in coactivation. During this study, similar methods took place. Converseley, Liu et al. (2006) registered increased coactivation in older adults during a countermovement jump (CMJ), and Hortobágyi \& DeVita (2000) evaluated agonist-antagonist coactivation during downward stepping. Nevertheless, a complex, multijoint, closed-chain, movement such as a CMJ or even downward stepping requires high levels of intermuscular coordination and neuromuscular efficiency in comparison to a simple opened-chain, single joint muscle action, like the leg extension used by Power, et al. (2013), or the arm flexion used by Pousson, et al. (2001). Thus, it is reasonable to notice an increased coactivation during multijoint, complex movements when compared to single joint, simple ones.

The mean CON representing all subjects in this study recorded greater values for CON $(110.3 \pm 24.1 \mathrm{Nm})$ compared to subjects in a similar study $(75.9 \pm 20.5 \mathrm{Nm})$. In that study, Hartmann, et. al (2009) tested a group ( $n=24 ; 6$ males, 18 females) of independent older adults (71.2 \pm 5.5 years), both sedentary and regular exercisers. In another study comparison, Symons, et al. (2005) included 12 women (73 \pm 7 years) and 18 men ( $73 \pm 5$ years), who completed a 12 week training program with a Biodex (three times per week) and were divided in 3 training groups (ECC, ISO and CON). When recruited, none of the subjects have practiced RT in the last 
6 months. Their base mean values were very similar to the values measured in this study for the

U group. Their mean CON $(128 \pm 52.3 \mathrm{Nm})$ was higher than the U group's CON $(101.1 \pm 24.96$

$\mathrm{Nm})$, their mean ISO $(121.8 \pm 42.73 \mathrm{Nm})$ was lower than the ISO for the U group $(137.1 \pm 35.17$

$\mathrm{Nm})$, and their mean ECC $(139.3 \pm 36.83 \mathrm{Nm})$ was lower than this study's U group's ECC

$(198.7 \pm 45.06 \mathrm{Nm})$. During their experiment, Symons, et. al (2005) randomly assigned subjects

to ECC, CON and ISO RT groups. All RT sessions were conducted exclusively on the Biodex.

The ECC RT group recorded the highest strength values of torque in all tests (ECC, CON, and

ISO) after completing the 12 week training protocol. The results exemplify the superior effects

of ECC RT (191.4 $\pm 76.8 \mathrm{Nm}$ for CON, $176.4 \pm 58.4 \mathrm{Nm}$ for ISO, and 207.1 Nm $\pm 35.6 \mathrm{Nm}$ for

ECC) in strength gains, when compared to the results for ISO RT $(151.8 \pm 61.2 \mathrm{Nm}$ for CON,

153.7 $\pm 57.2 \mathrm{Nm}$ for ISO, and 176.0 $\pm 44.7 \mathrm{Nm}$ for ECC), and CON RT (113.9 $\pm 48.3 \mathrm{Nm}$ for

CON, 104.2 $\mathrm{Nm} \pm 40.7$ for ISO, and 116.3 $\pm 26.1 \mathrm{Nm}$ for ECC).

\section{Summary}

According to the findings of this study, eccentric (ECC) strength is well maintained in older adults, regardless of training status, in contrast to concentric $(\mathrm{CON})$ strength and isometric (ISO) strength. The results confirmed that trained (T) older adults over 60 years of age produce significantly higher levels of relative CON torque and relative ISO torque, when compared to untrained (U) counterparts. However, no significant differences were found for relative ECC torque. When considering absolute values of strength, the findings showed significantly higher levels of ISO on the T group, but no significant differences between groups for ECC and CON. The maintenance of ECC is highly dependent on active and passive stiffness to resist loading forces into a given joint, and is of high importance to maintain functionality. Passive stiffness is 
generated by the viscoelastic properties of muscle and connective tissue. During old age, changes in muscle and connective tissue tend to increase passive stiffness, maintaining ECC to a greater extent than ISO and CON. ECC seems more dependent on mechanical qualities of muscle (i.e. spring like action of titin) and connective tissue (fascia, ligaments and tendons) in comparison to ISO and CON. The increase in collagen tissue found in aging muscles may also be important for ECC maintenance, as resistance to stretch increases. In addition, changes in active stiffness have been observed in older adults. Active stiffness has been measured and explained by an increased antagonist coactivation during complex, multijoint movements. These muscle recruitment strategies could be considered a protective mechanism to increase stiffness about a joint, augmenting stability. In addition, active stiffness could control range of motion, and might be helpful to limit the possibilities of facing extreme, external forces caused by increased, external moment arms that could incur injury. However, during simple, single joint movements, ECC seems more reliant on passive stiffness, with no increases in antagonist coactivation, when compared to younger subjects. 


\section{Chapter V}

\section{Summary and Conclusions}

\section{Summary}

Scientists are constantly investigating new ways to maintain health and functionality during old age. The maintenance of eccentric (ECC) strength has been explored and measured in older adults in comparison to younger subjects. ECC is considered of high importance to maintain functionality during old age. However, there is still not enough scientific evidence that clearly explains the precise mechanisms that support the maintenance of ECC when compared to isometric (ISO) and concentric (CON) strength.

This study had the participation of twenty volunteers (12 males, 8 females) of 60 to 81 years of age. Subjects were grouped as trained (T) and untrained (U), based on their previous six month, resistance training (RT) history. The experiment consisted of a single session of about 45 minutes, during which each subject was tested for leg extension strength on the dominant side, using a Biodex dynamometer. Testing order was randomized, including three maximal voluntary muscle actions of ISO, CON and ECC. Only the highest value for peak torque was used for data analysis for each condition. The ECC torque to ISO torque ratio (ECC: ISO) was calculated and compared across groups. The $\mathrm{T}$ group produced significantly higher ISO but no significant differences were found for ECC or CON. The ECC: ISO was significantly higher for the U group. This study serves as evidential material to support that ECC is well maintained in older adults, independently of training status.

The lack of physical activity is known to accelerate aging mechanisms and could induce pathological conditions. The loss of $\alpha$-motoneurons and the mechanisms of muscular cell 
apoptosis are known to reduce overall muscle mass and functionality and could cause sarcopenia (Cruz-Jentoft, et al., 2010; Narici \& Maffulli, 2010). Nevertheless, older adults are able to increase strength and induce muscle hypertrophy with exercise. RT has been recognized as an alternative to control and revert the process of sarcopenia. Some of the measured adaptations of RT include improved strength, hypertrophy, fat loss, and overall, increased functionality (Henwood et al., 2008; Reeves et al., 2006). The maintenance of muscle mass is important for a healthy metabolism. Muscle mass reduces insulin resistance and helps maintaining a healthy basal metabolic rate (Clemmons, 2012). Furthermore, ECC RT may be more effective to increase strength and hypertrophy in older adults; however, ECC exercises are not commonly practiced in older adult training programs.

\section{Conclusions}

The present study suggests that older adults who have practiced resistance training, at least twice per week, for at least six months are stronger than people who do not practice resistance training or who do not meet the same training history than the trained group in this study. However, ECC is well maintained even in subjects who do not practice RT on a regular basis.

None of the subjects in this study have ever participated in an ECC biased resistance training program. Previous studies (Raj, et al., 2011; Reeves, et al., 2009; Symons, et al., 2005) have measured the effects of an ECC RT program in comparison to a regular RT program, showing superior strength gains and hypertrophy for ECC RT. Such evidence further demonstrates the potential not only to maintain but improve ECC in older adults, mainly to 
maintain and improve muscle mass and functionality, as well as to enhance fall-protective mechanisms.

\section{Future Research Recommendations}

It would be recommended to conduct a study with sedentary older adults in comparison to trained older adults to further examine the potential differences in ECC strength. More studies could include the measurement of stiffness during maximal ECC muscle actions, comparing trained and untrained individuals. It would be important to establish a clear difference between passive and active stiffness and their possible involvement in ECC maintenance. Additional studies could include ECC RT interventions in subjects with sarcopenia to measure possible effects on ECC in comparison to healthy subjects.

\section{Possible Practical Applications}

It is evident that individuals who practice RT are stronger than those who do not. RT should continue to be promoted among older adults, especially to maintain or improve ISO and CON variables that are clearly more affected by lack of training in comparison to ECC. Training professionals should consider triphasic RT, including emphasis on ISO, ECC and CON phases of training in consecutive mesocycles to maximize strength, hypertrophy, and improve functionality. 


\section{References}

Akagi, R., Iwanuma, S., Hashizume, S., Kanehisa, H., Yanai, T., \& Kawakami, Y. (2012). In vivo measurements of moment arm lengths of three elbow flexors at rest and during isometric contractions. Journal of Applied Biomechanics, 28, 63-69.

Always, S. E. \& Siu, P. M. (2011). Nuclear apoptosis and sarcopenia. Sarcopenia-Age-Related Muscle Wasting and Weakness. 173-206.

Aoki, Y., Yarchoan, R., Wyvill, K., Okamoto, S., Little, R. F., Tosato, G. (2001). Detection of viral interleukin-6 in Kaposi sarcoma-associated herpesvirus-linked disorders. Blood (97), 2173-2176.

Babault, N., Pousson, M., Ballay, Y., \& Van Hoecke, J. (2001). Activation of human quadriceps femoris during isometric, concentric, and eccentric contractions. Journal of Applied Physiology, 91(6), 2628-2634.

Baumgartner, R. N., Koehler K. M., Gallagher, D., Romero, L., Heymsfield, S. B., Ross, R. R., Garry, P. J., \& Lindeman, R. D. (1998). Epidemiology of sarcopenia among the elderly in New Mexico. American Journal of Epidemiology, 147(8), 755-763.

Bamman, M. M., Hill, B. J., Adams, G. R., Haddad, F., Wetzstein, C. J., Gower, B. A., Ahmed, A., \& Hunter, G. R. (2003). Gender differences in resistance-training-induced myofiber hypertrophy among older adults. The Journals of Gerontology: Series A, 58(2), 108-116.

Bean, J. F., Kiely, D. K., Herman, S., Leveille, S. G., Mizer, K., Frontera, W. R., \& Fielding, R. A. (2002). The relationship between leg power and physical performance in mobility limited older people. Journal of The American Geriatric Society, 50: 461-467. 
Brack, A. S., Bildsoe, H., \& Hughes, S. M. (2005). Evidence that satellite cell decrement contributes to preferential decline in nuclear number from large fibres during murine agerelated muscle atrophy. Journal of Cell Science, 118, 4813-4821. doi:10.1242/jcs.02602

Caserotti, P., Aagaard, P., \& Simonsen, E. B. (2001). Contraction-specific differences in maximal muscle power during stretch-shortening cycle movements in elderly males and females. European Journal of Applied Physiology, 84(3), 206-212.

Clemmons, D. R. (2012). Metabolic Actions of Insulin-Like Growth Factor-I in Normal Physiology and Diabetes. Endocrinology and Metabolism Clinics of North America, 41(2), 425-443. DOI: 10.1016/j.ecl.2012.04.017

Clark, D. J., Condliffe, E. G., \& Patten, C. (2006). Activation impairment alters muscle torquevelocity in the knee extensors of persons with post-stroke hemiparesis. Clinical Neurophysiology, 117, 2328-2337.

Clark, D. J., Patten, C., Reid, K. F., Carabello, R. J., Phillips, E. M., \& Fielding, R. A. (2010). Impaired voluntary neuromuscular activation limits muscle power in mobility-limited older adults. The Journals of Gerontology: Series A, 65A(5), 495-502.

Cruz-Jentoft A. J., Baeyens, J. P., \& Bauer, J. M. (2010). Sarcopenia: European consensus on definition and diagnosis: report of the European Working Group on Sarcopenia in Older People. Age Ageing, 39, 412-423.

Cruz-Jentoft, A. J., Landi, F., Topinková, E., \& Michel, J. P. (January 01, 2010). Understanding sarcopenia as a geriatric syndrome. Current Opinion in Clinical Nutrition and Metabolic Care, 13(1), 1-7. 
Dalton, B. H., Power, G. A., Vandervoort, A. A., \& Rice, C. L. (2012). The age-related slowing of voluntary shortening velocity exacerbates power loss during repeated fast knee extensions. Experimental Gerontology,47(1), 85-92. doi:10.1016/j.exger.2011.10.010

D'Antona, G., Pellegrino, M. A., Carlizzi, C. N., \& Bottinelli, R. (2007). Deterioration of contractile properties of muscle fibres in elderly subjects is modulated by the level of physical activity. European Journal of Applied Physiology, 100(5):603-11.

Delmonico, M. J., Harris, T. B., Lee, J. S., \& Visser, M. (2007). Alternative definitions of sarcopenia, lower extremity performance, and functional impairment with aging in older men and women. Journal of the American Geriatrics Society, 55,(5), 769-774.

Deschenes, M. (2004). Effects of Aging on Muscle Fibre Type and Size. Sports Medicine, 34(12), 809824. doi:10.2165/00007256-200434120-00002

Enoka, R.M. (1996). Eccentric contractions require unique activation strategies by the nervous system. Journal of Applied Physiology, 81, 2339-2346.

Evans W. J., Morley J. E., Argiles J., Bales, C., Baracos, V., Guttridge, D., Jatoi, A., KalantarZadeh, K., Lochs, H., Mantovani, G., Marks, D., Mitch, W. E., Muscaritoli, M., Najand, A., Ponikowski, P., Rossi Fanelli, F., Schambelan, M., Schols, A., Schuster, M., Thomas, D., Wolfe, R., \& Anker, S. D. (2008). Cachexia: a new definition. Clinical Nutrition, 27, 793-799.

Evans, W. J. (2010). Skeletal muscle loss: cachexia, sarcopenia, and inactivity. The American Journal of Clinical Nutrition, 91(supplement):1123S-7S. doi: 10.3945/ ajcn.2010.28608A

Fling, B.W., Knight, C.A., \& Kamen, G. (2009). Relationships between motor unit size and recruitment threshold in older adults: implications for size principle. Experimental Brain Research, 197, 125-133. 
Flitney, F. W. \& Hirst, D. G. (1978). Cross-bridge detachment and sarcomere give, during stretch of active frog's muscle. Journal of Physiology, 276, 449-475.

Fried, L. P., Tangen, C. M., Walston, J., Newman, A. B., Hirsch, C., Gottdiener, J., et. al (2001). Frailty in older adults: evidence for a phenotype. The journals of gerontology, 56(3) M146-M156.

Fujinami, H., Nishizawa, N., Ogasawara, T., \& Kasuga, N. (2001). Eccentric exercise-induced morphological changes in the membrane systems involved in excitation-contraction coupling in rat skeletal muscle. Journal of Physiology, 533(2), 571-583.

Gabriel, D. A., Kamen, G. \& Frost, G. (2006). Neural adaptations to resistive exercise. Sports Medicine, 36(2), 133-149.

Grinnell, A., \& Brazier, M. A. B. (1981). The Regulation of muscle contraction: Excitationcontraction coupling. (6 ${ }^{\text {th }}$ Edition). New York: Academic Press.

Harman, E. (1993). Strength and Power: A definition of Terms. National Strength and Conditioning Association Journal, 15(6), 18-20.

Hartmann, A., Knols, R., Murer, K., \& de Bruin, E. D. (2009). Reproducibility of an isokinetic strength-testing protocol of the knee and ankle in older adults. Gerontology, 55:259-268, DOI: $10.1159 / 000172832$

Haskell, W. L., Lee, I. M., Pate, R. R., Powell, K. E., Blair, S. N., Franklin, B. A., Macera, C. A., Heath, G. W., Thompson, P. D., \& Bauman, A. (2007). Physical activity and public health: updated recommendation for adults from the American College of Sports Medicine and the American Heart Association. Medicine \& Science in Sports \& Exercise. doi: $10.1249 / \mathrm{mss} .0 \mathrm{~b} 013 \mathrm{e} 3180616 \mathrm{~b} 27$ 
Henwood, T. R., Riek, S., \& Taaffe, D. R. (2008). Strength Versus Muscle Power-Specific Resistance Training in Community-Dwelling Older Adults. The Journals of Gerontology Series A: Biological Sciences and Medical Sciences, 63(1), 83-91.

Herzog, W., Duvall, M., \& Leonard, T. R. (2012). Molecular mechanisms of muscle force regulation: A role for titin? Exercise and Sport Science Reviews, 40(1), 50-57.

Hobara, H., Kimura, K., Omuro, K., Gomi, K., Muraoka, K., Iso, S., Kanosue, K. (2008). Determinants of difference in leg stiffness between endurance- and power-trained athletes. Journal of Biomechanics, 41, 506-514.

Horowits, R., Kempner, E. S., Bisher, M. E., \& Podolsky, R. (1986). A physiological role for titin and nebulin in skeletal muscle. Nature, 323:160Y4.

Hortobagyi, T. \& DeVita, P. (2000). Muscle pre- and coactivity during downward stepping are associated with leg stiffness in aging. Journal of Electromyography and Kinesiology, 10, 117-126.

Hortobagyi, T. (2003). The Positives of negatives: Clinical implications of eccentric resistance exercise in old adults. Journal of Gerontology, 58A(5), 417-418.

Hortobagyi, T., Solnik, S., Gruber, A., Rider, P., Steinweg, K., Helseth, J., \& DeVita, P. (2009). Interaction between age and gait velocity in the amplitude and timing of antagonist muscle coactivation. Gait Posture, 29(4), 558-564.

Hunter, G. R., McCarthy, J. P. \& Bamman, M. M. (2004). Effects of resistance training on older adults. Sports Medicine, 34(5), 329-348.

Huxley, A. F., \& Niedergerke, R. (1954). Structural changes in muscle during contraction: Interference microscopy of living muscle fibres. Nature, 173(4412), 971-973. 
Ito, M., Kawakami, Y., Ichinose, Y., Fukashiro, S., \& Fukunaga, T. (1998). Nonisometric behavior of fascicles during isometric contractions of a human muscle. Journal of Applied Physiology, 85(4), 1230-1235.

Jang, Y. C. \& Van Remmen, H. (2011). Age-associated alterations of the neuromuscular junction. Experimental Gerontology, (46), 193-198.

Janssen I, Heymsfield, S. B, Baumgartner, R. N., \& Ross, R. (2000). Estimation of skeletal muscle mass by bioelectrical impedance analysis. Journal of Applied Physiology 89:465471.

Joumma, V., Rassier, D. E., Leonard, T. R., \& Herzog, W. (2008). The origin of passive force enhancement in skeletal muscle. American Journal of Physiology: Cell Physiology, 294: C74-C78. doi:10.1152/ajpcell.00218

Kallio, J., Søgaard, K., Avela, J., Komi, P. V., Selanne, H., \& Linnamo, V. (2013). Motor Unit firing behaviour of soleus muscle in isometric and dynamic contractions. PLoS ONE 8(2): e53425. doi:10.1371/journal.pone.0053425

Kato, E., Vieillevoye, S., Balestra, C., Guissard, N., \& Duchateau, J. (2011). Acute effect of muscle stretching on the steadiness of sustained submaximal contractions of the plantar flexor muscles. Journal of Applied Physiology (110), 407-415.

Kellermayer, M. S. Z., Smith, S. B., Granzier, H. L. M., Bustamante, C. (1997). Foldingunfolding transitions in single titin molecules characterized with laser tweezers. Science, 276:1112Y6.

Klass, M., Baudry, S., \& Duchateau, J. (2005). Aging does not affect voluntary activation of the ankle dorsiflexors during isometric, concentric, and eccentric contractions. Journal of Applied Physiology, 99, 31-38. 
Langberg, H., Ellingsgaard, H., Madsen, T., Jansson, J., Magnusson, P. S., Aagaard, P. \& Kjær, M. (2007). Eccentric rehabilitation exercise increases peritendinous type I collagen synthesis in humans with Achilles tendinosis. Scandinavian Journal of Medicine and Science in Sports, 17, 61-66.

Lastayo, P. C., Ewy, G. A., Pierotti, D. D., Johns, R. K., \& Lindstedt, S. (2003). The positive effects of negative work: Increased muscle strength and decreased fall risk in a frail elderly population. Journal of Gerontology: Medical Sciences, 58A, No. 5, 419-424.

Law, R., Y., W. \& Herbert, R., D. (2007). Warm-up reduces delayed-onset muscle soreness but cool-down does not: a randomised controlled trial. Australian Journal of Physiotherapy 53: 91-95.

Leonard, T. R., Joumaa, V., \& Herzog, W. (2010). An activatable molecular spring reduces muscle tearing during extreme stretching. Journal of Biomechanics, 43(15), 3063-3066.

Lee, E. J., Nedrud, J., Schemmel, P., Gotthardt, M., Irving, T. C., \& Granzier, H. L. (2013), Calcium sensitivity and myofilament lattice structure in titin N2B KO mice. Archives in Biochemestry and Biophysics. doi: 10.1016/j.abb.2012.12.004.

Leszczak, T. J., Olson, J.M., Stafford, J., \& Di Brezzo, R. (2013). Early adaptations to eccentric and high-velocity training on strength and functional performance in communitydwelling older adults. Journal of Strength and Conditioning Research, 27(2): 442-448.

Lindle, R. S., Metter, E. J., Lynch, N. A.,. Fleg, J. L., Fozard, J. T., Roy, T. A. \& Hurley, B. F. (1997). Age and gender comparisons of muscle strength in 654 women and men aged 2093 yr. Journal of Applied Physiology, 83:1581-1587.

Linke, W. A., \& Leake, M. C. (2004). Multiple sources of passive stress relaxation in muscle fibers. Physics in Medicine and Biology 49, 3613-3627. 
Liu, C. J., \& Latham, N. K. (2009). Progressive resistance strength training for improving physical function in older adults. Cochrane Database of Systematic Reviews, 3, CD002759.

Liu, Y., Peng, C.-H., Wei, S.-H., Chi, J.-C., Tsai, F.-R., \& Chen, J.-Y. (2006). Active leg stiffness and energy stored in the muscles during maximal counter movement jump in the aged. Journal of Electromyography and Kinesiology, 16(4), 342-351.

doi:10.1016/j.jelekin.2005.08.001

Martin, A.,Borlon, B., Pousson, M. \& Van Hoecke, J. (1996). Viscosity of the elbow flexor muscles during maximal eccentric and concentric actions. European Journal of Applied Physiology and Occupational Physiology, 73(1-2):157-62.

Martin, H. J., Yule, V., Syddall, H. E., Dennison, E. M., Cooper, C., \& Sayer, A. A. (2006). Is hand-held dynamometry useful for the measurement of quadriceps strength in older people? A comparison with the gold standard Biodex dynamometry. Gerontology, 52:154-159. DOI: 10.1159/000091824

Marzetti, E., Lawler, J. M., Hiona, A., Manini, T., Seo, A, Y, \& Leeuwenburgh, C. (2008). Modulation of age-induced apoptotic signaling and cellular remodeling by exercise and calorie restriction in skeletal muscle. Free Radical Biology \& Medicine. doi: 10.1016

Marzetti, E., Calvani, R, Bernabei, R., \& Leeuwenburgh, C. (2011). Apoptosis in skeletal myocytes: A potential target for interventions against sarcopenia and physical frailty. Gerontology, 58, 99-106. 
Mcneil, P. L. \& Khakee, R. (1992). Disruptions of muscle fiber plasma membrane. Role in exercise-induced damage. American Journal of Pathology 140, 1097-1109.

Naricci, M. V., \& Maffulli, N. (2010). Sarcopenia: characteristics, mechanisms and functional significance. British Medical Bulletin (95), 139-159.

Neil, S. E., Myring, A., Jef Petters, M., Pirie, I., Jacobs, R., et al. (2013). Reliability and validity of the Performance Recorder 1 for measuring isometric knee flexor and extensor strength. Physiotherapy Theory and Practice, 29(8) 639-647.

Nelson, W., Rejesk, J., Blair, S. N., , Duncan, P.W., OJudge, J. O., King, A.C., Macera, C. A., \& Castaneda-Sceppa, C. (2007). Physical activity and public health in older adults: recommendation from the American College of Sports Medicine and the American Heart Association. Journal of the American College of Sports Medicine DOI:10.1249/mss.0b013e3180616aa2

Nishikawa, K. C., Monroy, J. A., Uyeno, T. E., Yeo, S. H., Pai, D. K., \& Lindstedt, S. L. (2012). Is titin a 'winding filament'? A new twist on muscle contraction. Procedures of the Real Society B, 279, 981-990.

Ochala, J., Dorer, D. J., Frontera, W. R., \& Krivickas, L. S. (2006). Single skeletal muscle fiber behavior after a quick stretch in young and older men: a possible explanation of the relative preservation of eccentric force in old age. European Journal of Physiology, 452, 464-470.

Odetti, A. Borgoglio, A. \& Rolandi, R (1992) Age-related increase of collagen fluorescence in human subcutaneous tissue. Metabolism, 41(6):655-8. 
Parisea, G., Brosea, A. N., \& Tarnopolsky, M. A. (2005). Resistance exercise training decreases oxidative damage to DNA and increases cytochrome oxidase activity in older adults. Experimental Gerontology 40, 173-180.

Pousson M., Lepers R., \& Van Hoecke, J. (2001). Changes in isokinetic torque and muscular activity of elbow flexors muscles with age. Experimental Gerontology, 36, 1687-1698.

Power, G. A., Dalton, B. H., Rice, C. L., \& Vandervoort, A. A. (2011). Power loss is greater following lengthening contractions in old versus young women. Age, 34(3), 737750.

Power, G. A., Rice C. L., \& Vandervoort A. A. (2012). Increased residual force enhancement in older adults is associated with maintenance of eccentric strength. PLoS ONE 7(10): e48044. doi:10.1371/journal.pone.0048044

Power, G. A., Makrakos, D. P., Rice, C. L., \& Vandervoort, A. A. (2013). Enhanced force production in old age is not a far stretch: an investigation of residual force enhancement and muscle architecture. Physiological Reports, 1(1), n/a-n/a. doi:10.1002/phy2.4

Purslow, P. (2010). Muscle fascia and force transmission. Journal of Bodywork \& Movement Therapies, 14, 411-417.

Raj, I. S., Bird, S. R., Westfold, B. A., \& Shield, A. J. (2011) Effects of eccentrically biased versus conventional weight training in older adults. Medicine and Science in Sports \& Exercise, 44(6), 1167-1176. 
Reid, K. F., Doros, G., Clark, D. J.,Patten, C., Carabello, R. J., Cloutier, G. J., Phillips, E. M., Krivickas, L. S., Frontera, W. R., \& Fielding, R. A. (2012). Muscle power failure in mobility-limited older adults: preserved single fiber function despite lower whole muscle size, quality and rate of neuromuscular activation. European Journal of Applied Physiology, 112, 2289-2301.

Reeves, N. D., Narici, M. V., \& Maganaris, C. N. (2006). Musculoskeletal adaptations to resistance training in old age. Manual Therapy, 11(3), 192-196. doi:10.1016/j.math.2006.04.004

Roberts, T. J., \& Azizi, E. (2010).The series-elastic shock absorber: tendons attenuate muscle power during eccentric actions. Journal of Aplied Physiology, 109, 396404.

Roberts, T. J., \& Azizi, E. (2011). Flexible mechanisms: the diverse roles of biological springs in vertebrate movement. The Journal of Experimental Biology, 214, 353361.

Roig, M., O’Brien, K., Kirk, G., Murray, R., McKinnon, P., Shadgan, B., \& Reid, W. D. (2009). The effects of eccentric versus concentric resistance training on muscle strength and mass in healthy adults: a systematic review with meta-analysis. British Journal of Sports Medicine, 43, 556-568.

Rolland, Y., Abellan, V.K., Gillette-Guyonnet, S., \& Vellas, B. (2011). Cachexia versus sarcopenia. Current Opinion in Clinical Nutrition and Metabolic Care 2011, 14, 1521.

Schwartz, M. A. (2010). Integrins and extracellular matrix in mechanotransduction. Cold Spring Harbor Perspect Biology; doi: 10.1101. 
Sharif, S., Thomas, J. M, Donley, D. A., Gilleland,D. L., Bonner, D. E., et al. (2011). Resistance exercise reduces skeletal muscle cachexia and improves muscle function in rheumatoid arthritis. Case Reports in Medicine, Article ID 205691; doi:10.1155/2011/205691.

Sillanpaa, E., Hakkinen, K., Holviala, J., \& Hakkinen, A. (2012). Combined strength and endurance training improves health-related quality of life in healthy middle-aged and older adults. International Journal of Sports Medicine, 33(12), 981-6.

Simoneau, E. M., Longo, S., Seynnes, O. R. \& Narici, M. V. (2012), Human muscle fascicle behavior in agonist and antagonist isometric contractions. Muscle Nerve, 45, 92-99.

Skelton D. A, Greig C. A., Davies, J. M., \& Young A. (1994). Strength, power and related functional ability of healthy people aged 65-89 years. Age \& Ageing. 23(5):371-7.

Spudich, J. A. (2001). The myosin swinging cross-bridge model. Nature Reviews of Molecular Cell Biology, 2, 387-92.

Srikanthan, P. \& Karlamangla, A. S. (2011). Relative muscle mass is inversely associated with insulin resistance and prediabetes. Findings from The Third National Health and Nutrition Examination Survey. The Journal of Clinical Endocrinology \& Metabolism, 96(9), 2898-2903.

Symons T. B., Vandervoort, A. A., Rice, C. L., Overend, T. J., \& Marsh, G. D. (2005). Effects of maximal isometric and isokinetic resistance training on strength and functional mobility in older adults. Journal of Gerontology: Medical Sciences, 60A(6) 777-781. 
Szulc, P., Duboeuf, F., Marchand, F., Delmas, P. D. (2004). Hormonal and lifestyle determinants of appendicular skeletal muscle mass in men: the MINOS study. American Journal of Clinical Nutrition, 80, 496-503.

Takekura, H., Fujinami, H., Nishizawa, N., Ogasawara, T., \& Kasuga, N. (2001). Eccentric exercise-induced morphological changes in the membrane systems involved in excitation-contraction coupling in rat skeletal muscle. Journal of Physiology, 533(2), $571-583$.

Vaillancourt, D. E., Larsson, L., \& Newell, K. M. (2003). Effects of aging on force variability, single motor unit discharge patterns, and the structure of 10, 20, and $40 \mathrm{~Hz}$ EMG activity. Neurobiology of aging, 24(1), 25-35.

van Kan, G.A. (2009). Epidemiology and consequences of sarcopenia. The Journal of Nutrition, Health and Aging, 13(8), 708-712.

Walcott, S, \& Herzog, W. (2008). Modeling residual force enhancement with generic crossbridge models. Math Bioscience, 216:172Y86.

Whittington, B., Silder, A., Heiderscheit, B., \& Thelen, D.G. (2008). The contribution of passive-elastic mechanisms to lower extremity joint kinetics during human walking. Gait \& Posture, 27, 628-634.

Williams, C. D., Regnier, M., \& Daniel, T. L. (2012) Elastic energy storage and radial forces in the myofilament lattice depend on sarcomere length. PLoS Computational Biology, 8, 11: e1002770. doi:10.1371. 
Woo, J., Leung, J., \& Lau, E. (2009). Prevalence and correlates of musculoskeletal pain in Chinese elderly and the impact on 4-year physical function and quality of life. Public Health, 123, 549-556.

Wu, G., Zhao, F., Zhou, X., \& Wei, L. (2002). Improvement of isokinetic knee extensor strength and reduction of postural sway in the elderly from long-term Tai Chi exercise. Archives of Physical Medical Rehabilitation, 83, 1364-9. 
Appendix A:

Human Subjects Review Form and Informed Consent 


\section{What is your research question, or the specific hypothesis?}

The Null Hypothesis states: There will be no significant difference in eccentric, concentric, and isometric strength or eccentric to isometric ratio, while performing knee exercise between trained and untrained older adults.

\section{What are the potential benefits of the proposed research to the field?}

The human aging process has been extensively studied, looking for viable ways to maintain functionality and quality of life. Strength and power have been recognized as highly relevant measures of quality of life for elderly populations (Silanpaa, Hakkinen, Holviala, \& Hakkinen, 2012). Even though strength levels decrease with age, eccentric strength (ES) is maintained longer when compared to concentric and isometric strength in older adults (Power, Rice \& Vandervoort, 2012). However, the comparison of ES between trained and untrained older adults has not been measured. Eccentric strength is considered especially important for older populations. The natural function of generating force during muscle lengthening is to decelerate external and internal forces, which is important for daily function and injury prevention. ES improves posture and helps maintain balance. Thus, ES reduces the risk of falling, while improving functionality and overall quality of life (Wu, Zhao, Zhou, \& Wei, 2002). During this study, strength measurements while performing leg exercise of trained and untrained older adults will be compared, during each modality of muscle force production: concentric (shortening), isometric (static) and eccentric (lengthening) muscle actions. Possible differences in strength would be determined between groups and eccentric strength levels will be compared with isometric values, as a ratio function. This study compares muscular force production during all three types of muscle activity and contributes to further understanding the maintenance of strength in older adults. The findings could serve as valuable information with practical implications for training professionals, when designing resistance training programs for older populations.

\section{What are the potential benefits, if any, of the proposed research to the subjects?}

There may not be a direct benefit to the research subjects. They will be informed about the differences between isometric, concentric and eccentric exercise and their possible applications and benefits. The results of the experiment will serve as evidence to illustrate the impact of resistance training in the strength of older adults.

4. Answer a), then answer either b) or c) as appropriate. a. Describe how you will identify the subject population, and how you will contact key individuals who will allow you access to that subject population or database.

Thirty, injury-free, older men and women (over 60 years of age) will be recruited into two groups: trained and untrained. The trained group will be formed by the invitation of subjects who have participated in the Mature Adult Training Program (MATP) for at least 6 months at Western Washington University, with a frequency of 2-3 times per week. To recruit subjects for the untrained group, each recruited participant of the trained group will be asked to invite a friend or relative who has not been training in the last 6 months. Dr. Lorrie Brilla has affirmed that MATP participants may be contacted in the lower weight room in Carver Gym. Flyers will 
be posted and personal contact at the beginning of the workout session will be used to recruit subjects.

\section{b. Describe how you will recruit a sample from your subject population, including possible use of compensation, and the number of subjects to be recruited.}

Each willing participant forming the trained group will be asked to invite a friend who is not currently training, to participate in the untrained group. If the trained subject cannot convince an untrained friend to participate, then the Bellingham Senior Center may be contacted for sufficient untrained subjects to be recruited. The goal is to recruit a total of 30 subjects. There will be no compensation.

\section{c. Describe how you will access preexisting data about the subjects.}

Untrained subjects will be required to answer a health history questionnaire, including their history of training in the last 6 months. Trained subjects' health history information will be obtained from the training records documented for the participants of the Mature Adult Training Program at Western Washington University with subjects' authorization.

For trained subjects, the existing health history form will be reviewed. If the form was not completed within the past two years a new health history form will be completed. If any items in the health history are of concern, physician's clearance will be sought by the participant for the subject's participation.

\section{Briefly describe the research methodology. Attach copies of all test instruments/questionnaires that will be used.}

The research design is ex post facto, where subjects are evaluated in random order, for isometric, eccentric and concentric leg extension torque. Two groups will be formed based on training status, defined as trained and untrained. The testing session consists of three maximum voluntary muscle actions during concentric, eccentric and isometric leg extension torque.

Before testing, all subjects will complete the informed consent. Additionally, the untrained subjects will complete an activity questionnaire. Height and weight will be measured and recorded. Dominant leg is determined as the preferred leg to kick a ball.

Testing will be done using a Biodex dynamometer (Biodex, Shirley, NY), to measure maximum leg strength during isometric muscle action (static), and at a constant angular velocity of $120 \%$ sec, during concentric (muscle shortening) and eccentric (muscle lengthening) leg extension. This device adjusts the resistance provided to each subject, as it maintains the preset angular velocity during tests. A display shows the leg extensor force (torque) produced by each subject during testing.

Even though maximal effort exertion is not performed during the MATP program, MATP participants perform exercises $\geq 80 \%$ maximal effort, three times per week. Maximal strength testing is a regular practice in older adults for training, research and clinical purposes. For example, Schroeder, et al. (2007) reviewed data from three different studies that measured maximal strength in untrained men 60-87 years of age. Maximal strength was assessed safely 
and successfully during bilateral leg press, leg extension, leg flexion, latissimus pull-down (lat pull), and chest press exercises. During a high intensity strength training study, Fiatarone, et al (1990) found maximal strength testing is safe and effective even in noneagenarians.

In comparison, during this study, only leg extension will be tested. A recent article by authors from the Center for Disease Control and accompanying editorial in the journal, Circulation, 13 January, 2014, questioned unnecessary over referral of active individuals for medical clearance. Both trained and untrained individuals will be asked to provide current medical clearance by their physician.

Description of measurement techniques and testing procedures. Data collection will take place at Western Washington University in the Biomechanics Laboratory. A single session of approximately 45 minutes per subject will be required for data collection.

Each subject will be instructed to perform a general warm-up for 5 minutes using a cycle ergometer with no resistance added. Once the general warm-up is completed, the dominant leg will be defined by asking the subject to kick a soft, Poof-Slinky, 7-inch foam ball. The kicking leg will be defined as the dominant leg. Once dominant leg is defined, the subject will be briefly introduced to the Biodex (Biodex, Shirley, NY) and its function in the study. All tests will be performed exclusively on the dominant leg. The subject will be instructed to sit on the dynamometer's chair as proper adjustments are made, ensuring the center of rotation of the arm of the dynamometer are in alignment with the lateral femoral epicondyle of the dominant leg. For that purpose, the back of the seat will be adjusted and the length of the dynamometer's arm will be properly fitted to the length of the participant's shank. The shank pad will be positioned on the distal portion of the tibia (right above the ankle). The subject will be positioned sitting with a hip angle at about $80^{\circ}$. The participant will be stabilized with two shoulder straps, a waist strap, and a thigh strap, to reduce extraneous movements.

Once in proper position, each subject will be instructed to perform a warm-up, consisting of 3 sub-maximal contractions, at 60-70\% of isometric, maximum, voluntary contraction of the leg extensors, followed by a 2 minute rest at the original starting position of approximately $45^{\circ}$ of knee flexion. During the rest period, the order for the three testing conditions (isometric, concentric and eccentric) will be randomly defined by having the subject blindly select a colored marble out of a bag, to define which test is performed first. A second marble selection will determine the second test and the third test will be defined by the color of the remaining marble found in the bag. The assigned colors will be blue for isometric, green for concentric and red for eccentric. Based on the randomly selected test order, three maximum efforts for isometric, eccentric and concentric leg extensor muscle actions of the dominant thigh will be recorded. Every test for each condition will be followed by 2 minutes of rest. For the isometric test, the subject will push into leg extension against the dynamometer, starting at $60^{\circ}$ of knee flexion, with duration of 5 seconds per contraction, allowing 2 minutes of rest between repetitions. The eccentric and concentric tests will be performed at an angular velocity of $120 \%$ s, to mimic daily life muscle action speeds (Hartmann, et al. 2009). The range of motion will be from $20^{\circ}$ to $80^{\circ}$ of knee flexion, as the subject will be instructed to maximally resist the dynamometer as it moved towards leg flexion during eccentric, and as subject will push against the dynamometer into leg extension during concentric. A 2 minute resting period will be allowed between trials. After the completion of three attempts for each of the three conditions, each subject will be instructed to 
perform a cool down for 5 minutes on a cycle ergometer, at an easy pace, with no resistance added.

All subjects will be required to obtain physician's clearance for their participation in the study. The form shown in the next two pages will be presented to the physician. All subjects' participation in the experiment will be limited to written authorization by the physician. 
Physician's clearance to participate in the research project at Western Washington University entitled: "Eccentric, Concentric and Isometric Strength in Trained and Untrained Older Adults."

Purpose of the study. To measure and compare isometric, eccentric and concentric leg strength between trained and untrained older adults.

Description of measurement techniques and testing procedures. Data collection will take place at Western Washington University in the Biomechanics Laboratory. A single session of approximately 45 minutes per subject will be required for data collection.

- Each subject will be instructed to perform a general warm-up for 5 minutes using a cycle ergometer with no resistance added.

- Once the general warm-up is completed, the dominant leg will be defined by asking the subject to kick a soft, Poof-Slinky, 7-inch foam ball. The kicking leg will be defined as the dominant leg.

- A Biodex (Biodex, Shirley, NY) dynamometer will be used to measure maximal leg extension torque during the study. All tests will be conducted only on the dominant leg.

- The subject will be positioned sitting with a hip angle at about $80^{\circ}$. The participant will be stabilized with two shoulder straps, a waist strap, and a thigh strap, to reduce extraneous movements. Once in proper position, each subject will be instructed to perform a warm-up, consisting of 3 sub-maximal contractions, at $60-70 \%$ of isometric, maximum, voluntary contraction of the leg extensors, followed by a 2 minute rest at the original starting position of approximately $45^{\circ}$ of knee flexion. During the rest period, the order for the three testing conditions (isometric, concentric and eccentric) will be randomized.

- Based on the randomly selected test order, three maximum efforts for isometric, eccentric and concentric leg extensor muscle actions of the dominant thigh will be recorded. Every test for each condition will be followed by 2 minutes of rest.

- After the completion of three attempts for each of the three conditions, each subject will be instructed to perform a cool down for 5 minutes on a cycle ergometer, at an easy pace, with no resistance added. 


\section{STRENGTH TESTING FOR SENIORS}

Physician's Clearance to Participate in a Strength Study for Seniors

To the physician: Please read the Study Description that explains the procedures for this study. It is necessary to have this form completed before the participant can enroll in this study. Participants will be tested in leg extension strength, on the dominant leg. Three maximum exertions each of eccentric, concentric and isometric will be measured on a Biodex. Proper warm-up and cool-down will be performed by the subject.

\section{Participant's name:}

Have you read the Study Description that explains the testing procedures that will take place during the study?

YES NO Please request a copy before signing this clearance form

Are there any precautions that would limit maximal leg strength testing? If yes, explain

Are there any limitations not related to exercise?

Physician's recommendation:

Yes, it is my medical knowledge that the above patient may participate in a leg strength study for seniors.

Yes, it is my medical knowledge that the above patient may participate in a leg strength study for seniors with the following limitations:

No, it is my medical knowledge that the above patient should not participate in a leg strength study for seniors.

Physician's name

Physician's signature

Date 


\section{Give specific examples (with literature citations) for the use of your test instruments/questionnaires, or similar ones, in previous similar studies in your field.}

All testing will be performed using a Biodex dynamometer to measure leg extension torque. Similar measuring equipment was used by Hartmann, et al. (2009) to measure the reproducibility of an isokinetic strength test of knee and ankle in older adults. During their study, the reliability of the Biodex when testing older adults was documented. To measure the inter-rater reliability, one of the first two tests ( $\mathrm{t} 1$ or $\mathrm{t} 2$ ) was randomly chosen and compared to the second test ( $\mathrm{t} 3$ ). The intra-class correlation coefficients of the isokinetic measures ranged from 0.87 to 0.94 for leg extension tests at different velocities, with a standard error of measurement between 8.0 and 9.3\% demonstrating very good reliability of the Biodex.

Lower limb muscle strength has been considered an important determinant of physical function in older adults. In clinical and epidemiological settings, the Biodex has been considered the gold standard method to measure strength. Martin, et al. (2006) measured leg extensor strength using the Biodex as well as using a hand-held dynamometer in 20 men and women aged 61-81 years. The results showed that the hand held device undermeasured the quadriceps strength by $14.5 \mathrm{Nm}$ on average, with a more marked effect in stronger individuals. Such study supports the validity of the Biodex as a gold standard device for muscle strength measurement, commonly used in older adults. In a similar study, Symons, Vandervoort, Rice, Overned, \& Marsh (2005) used the Biodex to measure isokinetic and isometric leg extensor strength before and after 12 weeks of a resistance training program. Subjects in the study were twelve women ( $73 \pm 7$ years) and 18 men (73 \pm 5 years).

\section{Describe how your study design is appropriate to examine your question or specific hypothesis. Include a description of controls used, if any.}

To test the hypothesis in the study, leg extensor strength under eccentric, concentric and isometric conditions will be measured. Values between trained and untrained groups will be compared. The results may help illustrate how changes in muscle and connective tissue are useful to maintain eccentric strength during older age.

\section{Give specific examples (with literature citations) for the use of your study design, or similar ones, in previous similar studies in your field.}

The study design is ex post facto or after-the-fact research. The investigation starts after the fact without interference of the researcher. During this study, there will be no interventions but the training status of the recruited subjects serve to determine group assignment. Studies that measure strength are common, comparing torque during different conditions (eccentric, concentric and isometric) and/or comparing different groups. The Biodex is commonly used in research and is recognized as the gold standard method for strength measuring. Hartmann, Knols, Murer, \& de Bruin (2009) conducted a study to measure functional status in older adults, demonstrating very good reliability of the Biodex with their results.

In other studies, Power, Rice \& Vandervoort (2012) used a dynamometer to measure the difference in dorsiflexors strength between old and young adults after stretch. In other studies, 
Klass, et al. (2005) compared torque capacity in dorsiflexors of younger and older adults during isometric, concentric, and eccentric muscle actions.

The Biodex is an isokinetic dynamometer commonly used in clinical practice and research. It is safe and relatively easy to operate. It is not invasive and is fairly comfortable for the tested subject. More importantly, the Biodex is widely used in research for its testing reproducibility (Hartmann, Knols, Murer, \& de Bruin, 2009). As previously explained, the Biodex will be used to measure strength during the proposed study.

\section{Describe the potential risks to the human subjects involved.}

Exercising could induce delayed onset muscle soreness (DOMS) with a usual timeline of 24-72 hours after exercise. In particular, eccentric muscle actions are known to elicit DOMS. The acute degree of DOMS is significantly minimized in subjects with a recent resistance training history. Just like with any other type of exercise, there is a risk of cramping, pain, and muscular injury.

Gordon, et al. (1995) reviewed multiple studies to determine cardiovascular safety of maximal strength testing in healthy adults. During their investigation, Gordon, et al. (1995) corroborated that 1,819 maximal strength assessments took place between 1990 and 1993 in the Cooper Clinic (Dallas, TX) with no cases of clinically significant cardiovascular events in association with maximal strength testing. Between 1986 and 1993, about 4,500 different subjects completed about 20,000 maximal strength tests (Center for Exercise Science, University of Florida). The subjects were part of a population between 18-90 years of age. Gordon, et al. (1995) supported the cardiovascular safety of maximal strength testing in adults.

Unaccustomed eccentric muscle actions are known to induce muscle damage, causing a temporal loss of muscle strength, increased passive tension, and DOMS. Inflammation of connective tissue and degeneration of muscle fibers, along with temporal structural changes in cellular structures are known to take place, after a bout of unaccustomed eccentric exercise (Howatson \& Somerel, 2012).

Paulsen, et al. (2010) measured the accumulation of leukocytes (white blood cells) after maximal, unaccustomed, eccentric muscle actions. Leukocytes fight inflammatory cells accumulated after muscle damage. During the study, subjects performed 300 maximal exertions of eccentric, leg extension. Muscle biopsies were collected 0.5, 4, 8, 24, 96, and 168 hours after exercise. In this study, none of the subjects were participating in heavy strength training and some of them were sedentary. As expected, a reduction of maximal force generating capacity was documented, recovering in the worst cases in a week (on the experimental leg only). However, results varied across subjects. The three subjects with the largest, acute loss of force generating capacity also showed the greatest accumulation of leukocytes in the exercised muscles. Perceived DOMS during stretching of the worked muscles peaked 47 hours after exercise. No significant soreness was reported for the muscle tendon junction, above the knee.

Jubeau, Muthalib, Millet, MaYuletti, \& Nosaka (2012) measured blood markers of muscle damage and DOMS after isometric arm flexor, muscle actions. After warming up with 5-6 submaximal isometric muscle actions, each subject performed four maximal isometric muscle actions. The study findings demonstrated muscle damage and DOMS after isometric maximum voluntary contractions. 
Maximal strength testing is commonly performed with free weights, machine weights or a dynamometer (i.e., a Biodex). However, a Biodex allows the subject to determine the extent of their effort in contrast to external loads that are used with free or machine weights that are used for maximal strength testing.

\section{If the research involves potential risks, describe the safeguards that will be used to minimize such risks.}

To minimize risk and ensure safety of all subjects, a proper warm-up will be performed by each subject. A general warm-up for 5 minutes using a cycle ergometer with no resistance added. Additionally, each subject will be introduced and familiarized with the Biodex before performing maximal strength testing and will complete a specific warm-up, consisting of 3 sub-maximal contractions, at $60-70 \%$ of maximum, isometric voluntary contraction. All procedures will be under strict supervision of a seasoned, certified personal trainer to ensure safety. The trained group will be recruited from the Western Washington University's Mature Adult Training Program, during which they have been familiarized with resistance training for at least 6 months. During this study, the test involves a total of only nine repetitions of leg extension, in comparison to their regular resistance training program, which includes multiple sets of more than 10 repetitions. Thus, if DOMS were present in the trained group it would decrease sooner due to the subjects' prior exposure to exercise. To minimize fatigue, a 2-minute rest period will be granted between each test, for every subject.

Even if DOMS were present for the untrained group, the effects would not be expected to last for more than 24-72 hours. Nine repetitions is a minimal number of the exercise and is so unlikely to elicit DOMS. The experimental design includes proper warm-up and cool-down. Law \& Herbert (2007) found a small reduction in DOMS in subjects who performed unaccustomed eccentric exercise preceded by a warm-up. DOMS is caused by the damage of stretched muscle fibers under tension during eccentric exercise. Warm-up benefits include a temperature augmentation in muscle fibers that could increase their compliance. Increased compliance could reduce the degree of muscle fiber stretch under tension with a consequent reduction of muscle damage.

Post-exercise muscle soreness, also known as delayed-onset muscle soreness (DOMS), is defined as the sensation of discomfort or pain in the skeletal muscles following physical activity, usually eccentric, to which an individual is not accustomed. DOMS is usually associated with a new type of training stimulus, not necessarily a heavy or more intense load (Howatson \& Somerel, 2012).

The incidence of DOMS is difficult to calculate, because most people who experience it do not seek medical attention, instead accepting DOMS as a temporary discomfort. Every healthy adult most likely has developed DOMS on countless occasions, with the condition occurring regardless of the person's general fitness level. Treatment, if any, is to use exercise-induced analgesia by performing exercise or NSAIDs.

Maximal strength testing has been extensively used in research and has been common practice to establish basal levels of strength for proper exercise prescription. During their study, Shaw, McCully \& Posner (1995) studied the risk of injury during maximal strength testing in adults 55- 
80 years of age. Eighty-three subjects were tested during five different exercises: leg extension, chest press, calf raise, abdominal curl, and arm curl, with an average of 6 attempts per exercise to reach a maximal value of strength. After the procedures, all subjects completed a questionnaire reporting muscle soreness or injury. There were two injuries reported by two subjects, representing $2.4 \%$ of the population. Both subjects were inexperienced in resistance training. One of the injuries occurred during chest press and the second one during leg extension. However, the injury caused by maximal leg extension was related to a previously existing orthopedic condition that was mentioned during the pre-screening process. Further, fifty-eight subjects reported DOMS. The mean score on a 4-point scale of soreness was $2.3 \pm 0.7$, but was not reported in any case as severe enough to impair exercise or daily activities. These findings conclude that maximal strength testing can be safe for older populations, with no serious, lifethreatening or permanent disability risks.

During the proposed study, only leg extension will be tested. Subjects with reported joint pain or previous health problems that could represent risk of an injury will be excluded from testing. More importantly, a physician's release for exercising will be required for all subjects. Caution, proper instruction and supervision will be ensured when performing maximal strength testing.

\section{Describe how you will address privacy and/or confidentiality.}

Each subject will be assigned a number for identification during the study to ensure confidentially. All data and subject information will be kept private from any individual who is not helping with data collection. Any publication of the work will keep subjects anonymity.

12. If your research involves the use of schools (pre-kindergarten to university level) or other organizations (e.g., community clubs, companies), please attach a clearance letter from an administrator from your research site indicating that you have been given permission to conduct this research. For pre-kindergarten to grade 12 level schools, an administrator (e.g. principal or higher) should issue the permission. For post-secondary level schools the class instructor may grant permission. For Western Washington University, this requirement of a clearance letter is waived if you are recruiting subjects from a scheduled class. If you are recruiting subjects from a campus group (not a class) at Western Washington University, you are required to obtain a clearance letter from a leader or coordinator of the group. 
Volunteer copy / Investigator copy

\title{
INFORMED CONSENT FORM WESTERN WASHINGTON UNIVERSITY
}

\author{
Title of Investigation: $\quad$ Strength in Trained and Untrained Older Adults \\ Investigator: $\quad$ Fernando Rosete
}

Phone: (206) 552-3103

Email: rosetef@students.wwu.edu

\section{Purpose of the Study:}

The study in which I am participating is designed to compare concentric strength, eccentric strength and isometric strength between trained and untrained older adults. The results could help illustrate how changes in muscle and connective tissue are useful to maintain eccentric strength during older age. Furthermore, this study could help illustrate a possible interaction between training status and strength.

\section{Procedures to be followed:}

I understand that males and females will be invited to this study involving leg strength testing on a dynamometer. I understand that in order to participate in the study:

- I must be over 60 years of age

- I must be willing to attend a 40 minute data collection session.

Test session procedures: (time commitment: 40 minutes):

- The total time commitment to the project is approximately 10 minutes of set up and paper work, and approximately 30 minutes of testing, including a warm-up and cool down

- Any questions that I have will be answered at the time.

- My height and weight will be determined with the use of a scale and a stadiometer.

- I will blindly pick a total of two marbles out of a bag, one at a time, which will determine the order of the first two tests. The remaining marble in the bag will define the third test.

- My dominant leg will be determined as I am asked to kick a foam ball.

- I will be tested in the following areas:

I understand that prior to testing, I will perform a 5 minute warm-up on a stationary bike and I will be given a short period of time to get used to the Biodex device, and I will be requested to perform a few warm-up leg extension repetitions using the Biodex. Once warm-up is completed, I will be asked to perform three repetitions of maximal leg extension effort during three different conditions: concentric, eccentric and isometric muscle actions in the randomly established order. 
I understand that I will be allowed 2 minutes between each maximal effort, for a total of 9 repetitions during testing. The velocity of muscle action for concentric and eccentric muscle actions will be set at $120 \%$ s. I understand that every repetition requires $100 \%$ of my strength effort.

\section{Discomfort and Risks:}

I understand that exercise can lead to muscular soreness, cramping, pain, and fatigue. During testing, there is a risk of experiencing muscle soreness that should disappear after a period of rest. I understand that if exercise testing is painful, I can stop at any time. In addition, I am aware that I could experience delayed onset muscle soreness (DOMS) after the session that could last for 24-72 hours. Maximal strength testing is known to cause muscle damage during lengthening muscle actions. DOMS is associated with a normal inflammation initiated by the unaccustomed muscle exertion. The safeguards that will be used to minimize potential muscle soreness include a warm-up, acclimation and cool down period. However, if I feel like I cannot or should not perform any of these tasks, I could opt out from the participation in this study.

\section{Benefits to Subject:}

I understand that there may not be any direct benefits. I will be informed of the benefits of exercise and the possible training effects of concentric, isometric and eccentric training for my future application.

\section{Potential Benefits to Society:}

By participating in the study, I will contribute to the research in the maintenance of strength and strength differences between trained and untrained older adults. This will help to better understand whether strength is maintained as a natural process and the possible effects of exercise on concentric, isometric and eccentric strength. It will be possible to further explain the changes in concentric, isometric and eccentric strength in older age and the possible effects of exercise in the maintenance and promotion of strength.

\section{Statement of Confidentiality:}

I understand that any results will remain confidential with regard to my identity. I understand that the research team will follow strict rules to protect my privacy at all times during and after the study. I will be issued an ID number that will be the only marker associate with my data. My ID number and matching name will be kept in a secure electronic file. Only the investigator and his assistants will have access to my identity and to information that can be associated with my identity. In the event of publication of this research, no personal identification information will be disclosed.

The investigation and my part in the investigation have been defined and fully explained to me by the researchers and I understand the explanation. The procedures of this investigation and description of any risk and discomfort have been discussed in detail with me and I understand that a copy of the signed consent form will be provided to me. 


\section{Right to ask Questions:}

I have been given an opportunity to ask whatever questions I may have had and all such questions have been answered to my satisfaction.

I understand that I am free to deny any answers to specific items or questions in interviews or questionnaires. If I have any questions about this study, I can contact Fernando Rosete, at RoseteF@students.wwu.edu or by phone, at 206-552-3103 or Dr. Lorrie Brilla, at Lorrie.Brilla@wwu.edu or by phone, at 360-650-305.

I understand that for additional information about my rights as a research participant, I may contact Janai Symons at the WWU Human Protections Administrator (HPA), at 360-6503220. If any injury or adverse effect of this research is experienced you should contact Fernando Rosete, or the HPA, at:

Research and Sponsored Programs

Old Main Building 530

Western Washington University

Bellingham, WA 98225-9038

(360) 650-3220

\section{Compensation:}

I understand that I will receive no compensation for my participation in this study.

\section{Event of Injury:}

I understand that emergency medical care will be summoned in the event of injury resulting from this study. In the event of adverse effects related to this study, I understand that I shall contact Fernando Rosete or the HPA at the office listed above. I also understand that I am not waiving any rights that I may have against WWU for injury resulting from negligence of the University or investigators.

\section{Voluntary Participation:}

I understand that my participation in this study is voluntary, and that I may withdraw from this study at any time by notifying the investigator without consequences. I also understand that my participation may be terminated by the investigator if I do not fit any of the pre determined subject categories or if he or she feels that my personal well being is in question.

This is to certify that I am over the age of 60 years, and I consent to and give permission for my participation as a volunteer in this program of investigation. I understand that I will receive a signed copy of this consent form. I have read this form, and understand the content of this consent form. 
Volunteer's printed name

Volunteer's signature
Date

\section{Date}

I, the undersigned, have fully explained the investigation to the above subject.

Investigator's printed name

Date

Investigator's signature

Date 


\section{Appendix B:}

Permission forms to contact possible subjects for testing 


\section{PERMISSION FORM TO CONTACT MATURE ADULTS FOR TESTING (WWU) \\ Letter of permission:}

As the director of the Mature Adult Training Program of the Western Washington University, I, , consent to allow Fernando Rosete's thesis research to recruit the WWU Mature Adult Training Program participants, which includes maximal leg extension strength testing, during isometric (static), eccentric (muscle lengthening) and concentric (muscle shortening) conditions.

Program Director's Name (Printed)

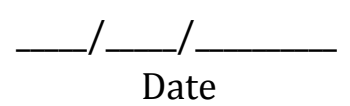

Program Director's Signature 


\section{PERMISSION FORM TO CONTACT SENIORS FOR TESTING (BSAC)}

\section{Letter of permission:}

As the manager of the Bellingham Senior Activity Center, I, consent to allow Fernando Rosete's thesis research to recruit the members of the Bellingham Senior Activity Center, which includes maximal leg extension strength testing, during isometric (static), eccentric (muscle lengthening) and concentric (muscle shortening) conditions.

Director's Name (Printed)

$\frac{1}{\text { Date }} /$

Director's Signature 
Appendix C:

Physical Activity Readiness Questionnaire (PAR-Q) 
PHYSICAL ACTIVITY READINESS QUESTIONNAIRE (PAR-Q)

NAME:

HEIGHT:

in.

WEIGHT:

lbs.

DATE:

PHYSICIANS NAME: PHONE:

\begin{tabular}{|c|c|c|c|}
\hline & Questions & Yes & No \\
\hline 1 & $\begin{array}{l}\text { Has your doctor ever said that you have a heart condition and that you should } \\
\text { only perform physical activity recommended by a doctor? }\end{array}$ & & \\
\hline 2 & Do you feel pain in your chest when you perform physical activity? & & \\
\hline 3 & $\begin{array}{l}\text { In the past month, have you had chest pain when you were not performing any } \\
\text { physical activity? }\end{array}$ & & \\
\hline 4 & $\begin{array}{l}\text { Do you lose your balance because of dizziness or do you ever lose } \\
\text { consciousness? }\end{array}$ & & \\
\hline 5 & $\begin{array}{l}\text { Do you have a bone or joint problem that could be made worse by a change in } \\
\text { your physical activity? }\end{array}$ & & \\
\hline 6 & $\begin{array}{l}\text { Is your doctor currently prescribing any medication for your blood pressure or } \\
\text { for a heart condition? }\end{array}$ & & \\
\hline 7 & $\begin{array}{l}\text { Do you know of any other reason why you should not engage in physical } \\
\text { activity? }\end{array}$ & & \\
\hline
\end{tabular}

If you have answered "Yes" to one or more of the above questions, consult your physician before engaging in physical activity. Tell your physician which questions you answered "Yes" to. After a medical evaluation, seek advice from your physician on what type of activity is suitable for your current condition. 


\section{PAR-Q, page 2:}

\begin{tabular}{|c|c|c|c|}
\hline & Occupational Questions & Yes & No \\
\hline 1 & What is your current occupation? & & \\
\hline 2 & Does your occupation require extended periods of sitting? & & \\
\hline 3 & $\begin{array}{l}\text { Does your occupation require extended periods of repetitive movements? (If yes, } \\
\text { please explain.) }\end{array}$ & & \\
\hline 4 & Does your occupation require you to wear shoes with a heel (dress shoes)? & & \\
\hline 5 & Does your occupation cause you anxiety (mental stress)? & & \\
\hline & Recreational Questions & Yes & No \\
\hline 6 & $\begin{array}{l}\text { Do you partake in any recreational activities (golf, tennis, skiing, etc.)? (If yes, please } \\
\text { explain.) }\end{array}$ & & \\
\hline 7 & $\begin{array}{l}\text { Do you have any hobbies (reading, gardening, working on cars, exploring the Internet, } \\
\text { etc.)? (If yes, please explain.) }\end{array}$ & & \\
\hline & Medical Questions & Yes & No \\
\hline 8 & $\begin{array}{l}\text { Have you ever had any pain or injuries (ankle, knee, hip, back, shoulder, etc.)? } \\
\text { (If yes, please explain.) }\end{array}$ & & \\
\hline 9 & Have you ever had any surgeries? (If yes, please explain.) & & \\
\hline 10 & $\begin{array}{l}\text { Has a medical doctor ever diagnosed you with a chronic disease, such as } \\
\text { coronary heart disease, coronary artery disease, hypertension (high blood } \\
\text { pressure), high cholesterol or diabetes? (If yes, please explain.) }\end{array}$ & & \\
\hline 11 & Are you currently taking any medication? (If yes, please list.) & & \\
\hline
\end{tabular}


Appendix D:

Data Collection Form 


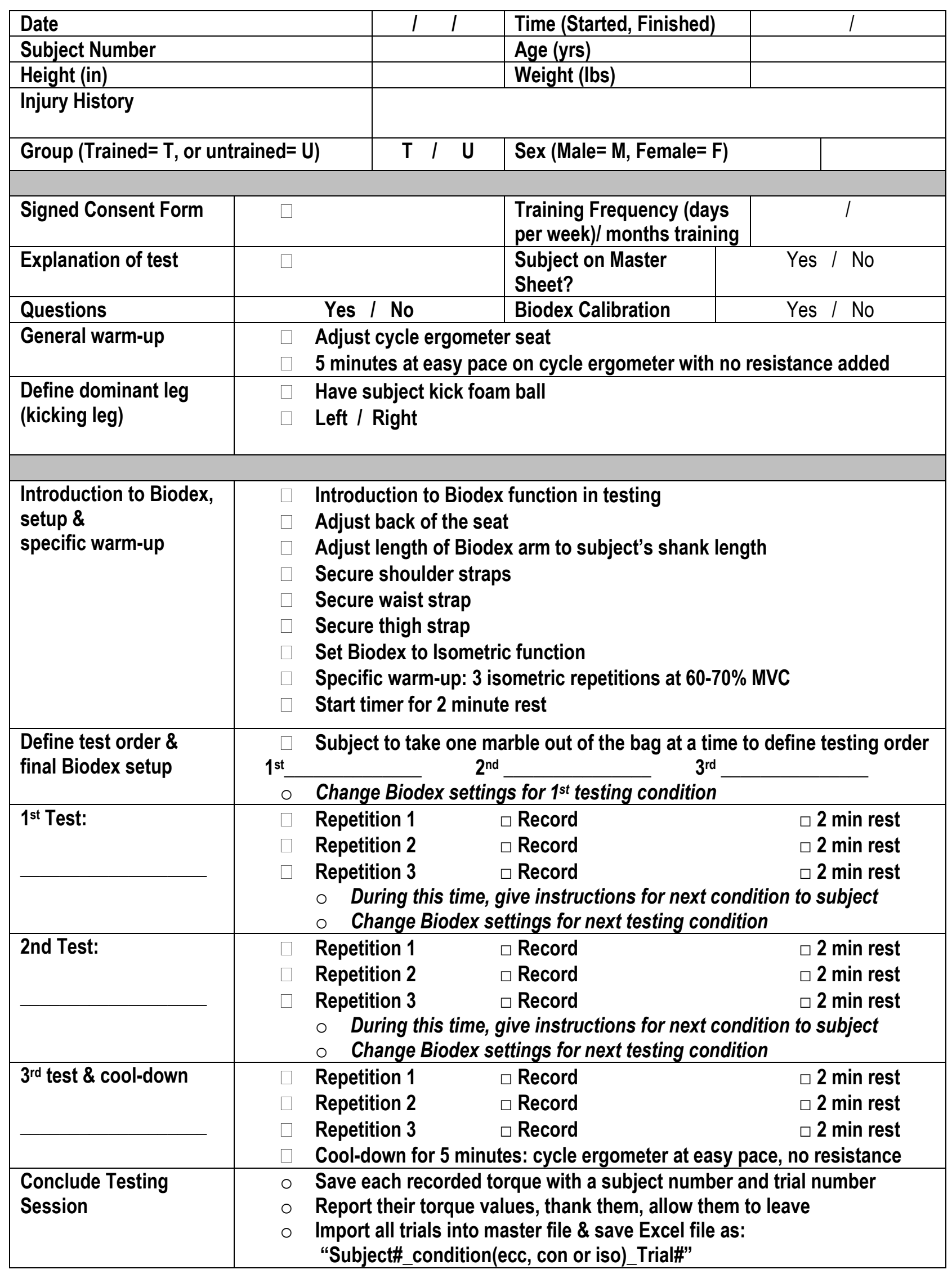


Appendix E:

Raw data 


\begin{tabular}{|c|c|c|c|c|c|c|c|c|c|c|}
\hline Subject & $\begin{array}{l}\text { Group } \\
(\mathrm{T}=1, \\
\mathrm{U}=2)\end{array}$ & Sex & $\begin{array}{l}\text { weight } \\
\text { (lbs) }\end{array}$ & $\begin{array}{l}\text { weight } \\
\text { (kgs) }\end{array}$ & $\begin{array}{l}\text { ISO } \\
\text { PkT } \\
(\mathrm{Nm})\end{array}$ & $\begin{array}{l}\text { ECC } \\
\text { PkT } \\
(\mathrm{Nm})\end{array}$ & $\begin{array}{l}\text { CON } \\
\text { PkT } \\
(\mathrm{Nm})\end{array}$ & ECC:ISO & Age & $\begin{array}{l}\text { Height } \\
\text { (in) }\end{array}$ \\
\hline 1 & 2 & $\mathrm{~F}$ & 124.4 & 56.43 & 123.9 & 228.2 & 95.0 & 1.842 & 65 & 66 \\
\hline 2 & 1 & $\mathrm{M}$ & 176.0 & 79.83 & 230.6 & 294.1 & 140.3 & 1.275 & 73 & 68 \\
\hline 3 & 1 & $M$ & 136.2 & 61.78 & 195.5 & 230.3 & 118.8 & 1.178 & 73 & 67.5 \\
\hline 4 & 2 & $\mathrm{M}$ & 238.8 & 108.3 & 178.8 & 210.7 & 99.5 & 1.178 & 71 & 70 \\
\hline 5 & 1 & $\mathrm{M}$ & 200.0 & 90.72 & 218.7 & 267.6 & 143.6 & 1.224 & 68 & 70 \\
\hline 6 & 2 & $\mathrm{M}$ & 202.0 & 91.63 & 190.4 & 204.7 & 135.0 & 1.075 & 69 & 69 \\
\hline 7 & 2 & $\mathrm{~F}$ & 184.5 & 83.69 & 81.0 & 128.1 & 56.6 & 1.581 & 71 & 60 \\
\hline 8 & 1 & $\mathrm{M}$ & 192.0 & 87.09 & 233.0 & 295.9 & 145.4 & 1.270 & 67 & 67 \\
\hline 9 & 1 & $M$ & 159.0 & 72.12 & 140.5 & 133.8 & 94.2 & 0.952 & 79 & 65 \\
\hline 10 & 2 & $\mathrm{~F}$ & 159.5 & 72.35 & 105.5 & 139.4 & 68.5 & 1.321 & 74 & 65 \\
\hline 11 & 2 & $\mathrm{~F}$ & 183.0 & 83.01 & 129.3 & 190.7 & 96.5 & 1.475 & 68 & 64.5 \\
\hline 12 & 2 & $M$ & 146.0 & 66.22 & 132.9 & 248.2 & 100.1 & 1.868 & 79 & 66 \\
\hline 13 & 2 & $M$ & 234.0 & 106.1 & 178.5 & 254.8 & 128.7 & 1.427 & 74 & 73 \\
\hline 14 & 1 & $\mathrm{~F}$ & 154.0 & 69.85 & 162.4 & 202.5 & 106.0 & 1.247 & 65 & 60 \\
\hline 15 & 1 & $\mathrm{~F}$ & 247.0 & 112 & 197.2 & 210.1 & 138.0 & 1.065 & 60 & 69.5 \\
\hline 16 & 1 & $\mathrm{M}$ & 192 & 87.09 & 161.5 & 253.0 & 107.9 & 1.567 & 81 & 67 \\
\hline 17 & 1 & $\mathrm{~F}$ & 120 & 54.43 & 132.3 & 194.9 & 96.2 & 1.473 & 60 & 63 \\
\hline 18 & 2 & $\mathrm{M}$ & 169 & 76.66 & 116.2 & 152.9 & 106.4 & 1.316 & 67 & 67 \\
\hline 19 & 2 & $M$ & 192 & 87.09 & 134.7 & 229.7 & 124.8 & 1.705 & 67 & 69 \\
\hline 20 & 1 & $\mathrm{~F}$ & 142 & 64.41 & 166.0 & 181.5 & 104.6 & 1.093 & 60 & 67 \\
\hline
\end{tabular}


Appendix F:

Statistics Tables 


\begin{tabular}{|c|c|c|c|c|c|}
\hline \multicolumn{6}{|c|}{ Group Statistics } \\
\hline & GroupT1U2 & $\mathrm{N}$ & Mean & Std. Deviation & Std. Error Mean \\
\hline \multirow{2}{*}{ ISO PkT(Nm) } & 1.0 & 10 & 183.7700 & 36.43039 & 11.52030 \\
\hline & 2.0 & 10 & 137.1200 & 35.17385 & 11.12295 \\
\hline \multirow{2}{*}{ ECC PkT(Nm) } & 1.0 & 10 & 226.3700 & 51.91196 & 16.41600 \\
\hline & 2.0 & 10 & 198.7400 & 45.05698 & 14.24827 \\
\hline \multirow{2}{*}{ CON PkT (Nm) } & 1.0 & 10 & 119.5000 & 20.40915 & 6.45394 \\
\hline & 2.0 & 10 & 101.1100 & 24.95705 & 7.89211 \\
\hline \multirow{2}{*}{ ECCS: ISOS } & 1.0 & 10 & 1.2345 & .18311 & .05790 \\
\hline & 2.0 & 10 & 1.4789 & .26915 & .08511 \\
\hline \multirow{2}{*}{ ISO RS(Nm/kg) } & 1.0 & 10 & 2.4035 & .45317 & .14331 \\
\hline & 2.0 & 10 & 1.6659 & .35685 & .11285 \\
\hline
\end{tabular}




\begin{tabular}{|c|c|c|c|c|c|c|c|c|c|c|}
\hline \multicolumn{11}{|c|}{ Independent Samples Test } \\
\hline & & \multicolumn{2}{|c|}{$\begin{array}{l}\text { Levene's Test for Equality } \\
\text { of Variances }\end{array}$} & \multicolumn{7}{|c|}{$\mathrm{t}$-test for Equality of Means } \\
\hline & & \multirow[t]{2}{*}{$\mathrm{F}$} & \multirow[t]{2}{*}{ Sig. } & \multirow[t]{2}{*}{$\mathrm{t}$} & \multirow[t]{2}{*}{ df } & \multirow[t]{2}{*}{ Sig. (2-tailed) } & \multirow[t]{2}{*}{$\begin{array}{c}\text { Mean } \\
\text { Difference }\end{array}$} & \multirow[t]{2}{*}{$\begin{array}{l}\text { Std. Error } \\
\text { Difference }\end{array}$} & \multicolumn{2}{|c|}{$\begin{array}{l}95 \% \text { Confidence Interval of } \\
\text { the Difference }\end{array}$} \\
\hline & & & & & & & & & Lower & Upper \\
\hline \multirow{2}{*}{ ISO PkT (Nm) } & $\begin{array}{l}\text { Equal variances } \\
\text { assumed }\end{array}$ & .240 & .630 & 2.913 & 18 & .009 & 46.65000 & 16.01366 & 13.00655 & 80.29345 \\
\hline & $\begin{array}{l}\text { Equal variances not } \\
\text { assumed }\end{array}$ & & & 2.913 & 17.978 & .009 & 46.65000 & 16.01366 & 13.00358 & 80.29642 \\
\hline \multirow{2}{*}{ ECC PkT (Nm) } & $\begin{array}{l}\text { Equal variances } \\
\text { assumed }\end{array}$ & .198 & .661 & 1.271 & 18 & .220 & 27.63000 & 21.73703 & -18.03780 & 73.29780 \\
\hline & $\begin{array}{l}\text { Equal variances not } \\
\text { assumed }\end{array}$ & & & 1.271 & 17.651 & .220 & 27.63000 & 21.73703 & -18.10267 & 73.36267 \\
\hline \multirow{2}{*}{ CON PkT (Nm) } & $\begin{array}{l}\text { Equal variances } \\
\text { assumed }\end{array}$ & .002 & .968 & 1.804 & 18 & .088 & 18.39000 & 10.19504 & -3.02898 & 39.80898 \\
\hline & $\begin{array}{l}\text { Equal variances not } \\
\text { assumed }\end{array}$ & & & 1.804 & 17.318 & .089 & 18.39000 & 10.19504 & -3.08963 & 39.86963 \\
\hline \multirow{2}{*}{ ECCS: ISOS } & $\begin{array}{l}\text { Equal variances } \\
\text { assumed }\end{array}$ & 2.039 & .170 & -2.375 & 18 & .029 & -.24444 & .10294 & -.46072 & -.02817 \\
\hline & $\begin{array}{l}\text { Equal variances not } \\
\text { assumed }\end{array}$ & & & -2.375 & 15.861 & .031 & -.24444 & .10294 & -.46282 & -.02606 \\
\hline \multirow{2}{*}{ ISO RS (Nm/kg) } & $\begin{array}{l}\text { Equal variances } \\
\text { assumed }\end{array}$ & .584 & .455 & 4.043 & 18 & .001 & .73752 & .18240 & .35431 & 1.12074 \\
\hline & $\begin{array}{l}\text { Equal variances not } \\
\text { assumed }\end{array}$ & & & 4.043 & 17.062 & .001 & .73752 & .18240 & .35279 & 1.12225 \\
\hline
\end{tabular}




\begin{tabular}{|l|l|r|r|r|r|}
\hline \multicolumn{7}{|c|}{ Group Statistics } \\
\hline \multirow{2}{*}{ Ecc RS } & GroupT1U2 & $\mathrm{N}$ & \multicolumn{1}{|c|}{ Mean } & Std. Deviation & Std. Error Mean \\
\cline { 2 - 7 } & 1.0 & 10 & 2.9692 & .67608 & .21380 \\
\hline \multirow{3}{*}{ Con RS } & 1.0 & 10 & 2.4759 & .81019 & .25621 \\
\cline { 2 - 7 } & 2.0 & 10 & 1.5619 & .23744 & .07509 \\
& 1.0 & 10 & 1.2406 & .31585 & .09988 \\
\hline
\end{tabular}

\begin{tabular}{|c|c|c|c|c|c|c|c|c|c|c|}
\hline \multicolumn{11}{|c|}{ Independent Samples Test } \\
\hline & & \multicolumn{2}{|c|}{$\begin{array}{l}\text { Levene's Test for Equality of } \\
\text { Variances }\end{array}$} & \multicolumn{7}{|c|}{ t-test for Equality of Means } \\
\hline & & \multirow[t]{2}{*}{$\mathrm{F}$} & \multirow[t]{2}{*}{ Sig. } & \multirow[t]{2}{*}{$\mathrm{t}$} & \multirow[t]{2}{*}{ df } & \multirow[t]{2}{*}{ Sig. (2-tailed) } & \multirow[t]{2}{*}{$\begin{array}{c}\text { Mean } \\
\text { Difference }\end{array}$} & \multirow[t]{2}{*}{$\begin{array}{l}\text { Std. Error } \\
\text { Difference }\end{array}$} & \multicolumn{2}{|c|}{$\begin{array}{l}95 \% \text { Confidence Interval of } \\
\text { the Difference }\end{array}$} \\
\hline & & & & & & & & & Lower & Upper \\
\hline \multirow{2}{*}{ ECC RS } & $\begin{array}{l}\text { Equal variances } \\
\text { assumed }\end{array}$ & .221 & .644 & 1.478 & 18 & .157 & .49333 & .33369 & -.20773 & 1.19439 \\
\hline & $\begin{array}{l}\text { Equal variances not } \\
\text { assumed }\end{array}$ & & & 1.478 & 17.441 & .157 & .49333 & .33369 & -20934 & 1.19601 \\
\hline \multirow{2}{*}{ CON RS } & $\begin{array}{l}\text { Equal variances } \\
\text { assumed }\end{array}$ & 1.052 & .319 & 2.571 & 18 & .019 & .32122 & .12496 & .05869 & .58374 \\
\hline & $\begin{array}{l}\text { Equal variances not } \\
\text { assumed }\end{array}$ & & & 2.571 & 16.710 & .020 & .32122 & .12496 & .05723 & .58520 \\
\hline
\end{tabular}

